\title{
Participation in Job-related Training - Is There a Parenthood Training Penalty?
}

Gundula Zoch ${ }^{1}$

[Accepted version published as: Zoch, Gundula (2022): Participation in Job-Related Training - Is There a Parenthood Training Penalty? In: Work, Employment and Society, 0(0), 1-19. DOI: 10.1177/09500170221128692]

\begin{abstract}
Gender inequalities in paid and unpaid work are well documented, but patterns of advantage or disadvantage in further job-related training have been less explored. Previous crosssectional studies indicate gender differences, with lower participation rates and shorter trainings for women, especially mothers. Based on the National Educational Panel Study for Germany (adult cohort, 2008-2020), this study is the first to examine gendered parenthood effects on participation in non-formal further job-related training using panel analyses. The results from fixed-effects regressions provide evidence of parenthood training penalties that are particularly pronounced for mothers and in the first years after the birth of their child. While fatherhood training penalties are mostly explained, motherhood gaps remain robust when accounting for a large number of time-varying characteristics. The results point towards further relevant changes in mothers' aspirations or employer support. Thus, they underline the importance of training opportunities for reducing childbirth-related inequalities later in life.
\end{abstract}

Keywords: Adult education, childbirth, family work, fixed-effects, further training, gender inequalities, labour market inequalities, maternal employment, parenthood

Acknowledgements: The author would like to thank Franka Birkenbach for her assistance in preparing the online supplementary in her capacity as a student assistant. The author is grateful for comments on an earlier version of this article from participants at the RC28 Conference 2021 and helpful suggestions from those at invited seminars at University of Bamberg, the CSIS Brown Bag Seminar at the University of Trento and the Research Centre for Education and the Labour Market at the University of Maastricht.

This paper uses data from the National Educational Panel Study (NEPS; see Blossfeld \& Roßbach, 2019). The NEPS is carried out by the Leibniz Institute for Educational Trajectories (LIfBi, Germany) in cooperation with a nationwide network.

\footnotetext{
${ }^{1}$ University of Oldenburg, Ammerlander Heerstr. 114-118, 26111 Oldenburg

Leibniz Institute for Educational Trajectories, Wilhelmsplatz 3, 96047 Bamberg, Germany

E-Mail: gundula.zoch@uni-oldenburg.de, ORCID iD: 0000-0002-4398-4535
} 


\section{Participation in Job-related Training - Is There a Parenthood Training Penalty?}

\section{Introduction}

The birth of a child is associated with increased gender inequalities in employment and family work, so that the effect of parenthood on the probability to participate in job-related training is also likely to differ between men and women. Research shows that childbirth alters women's employment more than men's (Steiber and Haas, 2012) while increasing their relative share of family work (Schober and Zoch, 2019). Therefore, it is highly likely that mothers also face a more severe disadvantage in training participation, particularly for jobrelated training. First studies acknowledge gender training gaps as another potential driver of persistent gender inequalities in paid employment and career trajectories (Evertsson, 2004; Havet and Sofer, 2008).

So far, the limited evidence on parenthood differences in further training participation stems almost exclusively from cross-sectional studies (Boll and Bublitz, 2018; Dämmrich et al., 2016; Dieckhoff and Steiber, 2011). Without longitudinal data, however, these studies cannot investigate whether and how men and women change their participation in job-related training due to childbirth. Moreover, previous studies examine a wide variety of training courses with differences in length and certification (longer formal vs shorter informal training), content (job-related or personal interest) or funding (private vs employer-sponsored), hence, results are difficult to compare.

This article examines the question of whether the birth of a child is linked to changes in participation in non-formal job-related training and whether the effect varies for women and men. The contribution of this article to the understanding of gendered labour market inequalities is threefold. First, by drawing on panel data with annual information on training 
participation, it is the first study that provides longitudinal evidence on the gendered effect of parenthood on job-related training participation. Therefore, this research narrows the focus on employed parents, concentrating exclusively on non-formal further education that is jobrelated short courses without a generally valid certificate, referred to as job-related training. ${ }^{1}$ Second, the article exploits longitudinal data, and thus, extensive pre- and post-birth information on the individual, household, organisational and occupational level, to show that altered training is mostly linked to changes in parent's paid and unpaid work and less influenced by changes in employer or occupation. Third, by comparing results from pooled linear probability models (LPM), conventional linear fixed-effects (FE) and fixed-effects regressions with individual slopes (FEIS), this study highlights the methodological importance of life-course approaches examining life events with a within-estimator. This way, the article presents a more causal examination of parenthood differences in job-related training, a key determinant of gender inequalities later in life (Evertsson, 2004; Havet and Sofer, 2008).

\section{Context of Germany}

In most Western societies, a rapidly ageing population and general technological change have increased the need to integrate broader population segments into the labour market, such as the low educated, the elderly and especially mothers with young children. Increasing maternal and promoting lifelong learning have therefore become important policy goals also in Germany. However, Germany is well known for its considerable low maternal employment rates, long family-related career breaks and high part-time employment rates. In 2007, Germany introduced a shortened and income-dependent parental leave benefit of 12 months at maximum for each parent and, since 2005 , has expanded public childcare coverage for the under threes to increase the maternal labour supply. This has enabled mothers to return to 
employment earlier (Zoch and Hondralis, 2017), however predominantly only in part-time, especially in West Germany (Zoch, 2020).

In addition to reducing employment barriers, the supply of and access to job-related training opportunities is crucial to meet the increased demand for skilled labour. Of all reported further education activities in Germany, the majority are non-formal trainings (54 \% of all individuals), followed by informal learning (45 \%) and longer formal education (11 \%) (figures for 2018, Federal Ministry of Education and Research (BMBF), 2019). Non-formal further training is primarily linked to (1) employer motives that initiate training and - to a lesser extent - (2) occupational regulations requiring specific training for certain jobs or tasks. As a result, employer-provided non-formal further training (72\%) predominates individual job-related training (10\%) and individual training related to private interests (18\%) (ibid.).

Further training is mainly offered in the occupational context, hence, gendered labour market inequalities are likely linked to gender gaps in job-related training (Blossfeld et al., 2020). Previous and current employment strongly determine training participation, especially for women, with more frequent employment interruptions and employer changes due to childbirth (Blossfeld et al., 2020; Havet and Sofer, 2008). According to official figures, men participate more frequently in job-related trainings (44 vs $36 \%$ ), while women are more likely to do trainings related to private interests (15 vs $11 \%$ ) (BMBF 2019). However, these figures do not distinguish between parents and childless individuals, hence, parenthood disparities in training cannot be examined.

Besides individuals' employment status, participation in job-related training depends strongly on the position, job tasks and employer. Individuals with higher educational levels, in good positions, with higher wages and in large companies with more institutionalised training support participate more often in training (BMBF 2019; Blossfeld et al., 2020). In a highly 
segmented labour market like Germany, training is crucial either for employer-specific tasks and internal labour markets or for more general tasks in occupational labour markets (Dämmrich et al., 2016). Employers are more likely to support employer-specific skill acquirement, promoting career development for internal jobs. Conversely, they are less likely to support training if the skills acquired can be used in other organisations (Blossfeld et al., 2020) and employees have a high risk of job and employer change, such as mothers (Dämmrich et al., 2016; Havet and Sofer, 2008).

Finally, differences in job-related training participation are also related to occupations providing the most important link between social stratification in educational trajectories and the labour market (Blossfeld et al., 2020). Individuals with vocational training acquire more employer-specific skills and subsequently participate less in training than those with higher education levels but more general skills and thus high employer- and job-specific training needs (Wotschack, 2019). Female-dominated occupations, in particular, are linked to stateprovided general educational tracks, so demand for employer- and job-specific skills is larger than in male-dominated occupations, e.g. in the health and social services sector (Wotschack, 2019). Accordingly, training rates are generally higher for women, especially for those with general educational qualification.

\section{Background and Hypotheses}

Although most training is job-related and gendered inequalities remain of great relevance in most Western labour markets, evidence on gender and parental differences in further training is mixed. Various - mostly cross-sectional - studies highlight a female training disadvantage (Burgard, 2012; Dämmrich et al., 2016; Dieckhoff and Steiber, 2011; Evertsson, 2004; Massing and Gauly, 2017), i.e. lower training rates, no or only small gender differences (e.g., Barry et al., 2020; Kaufmann and Widany, 2013) or even higher female training rates (Burgard, 2012; 
Dämmrich et al., 2016). However, only a few studies focus explicitly on gender differences in job-related training, whereas most studies examine gender disparities among other social inequalities. In addition, only a few cross-sectional studies examine parental differences in job-related training, showing parenthood penalties primarily for mothers and job-related training (Boll and Bublitz, 2018; Burgard, 2012; Dieckhoff and Steiber, 2011; Massing and Gauly, 2017; Dämmrich et al., 2016), with particularly pronounced disparities in contexts with few employment-oriented family policies. Moreover, evidence varies widely regarding how further training is defined (formal, non-formal or informal) or whether training is closely linked to employment or even provided by the employer.

Although empirical research is inconclusive, sociological and economic theories of the labour market suggest several reasons why women, and particularly mothers, are less likely to participate in job-related training than men. By applying a demand and supply perspective, these reasons can be differentiated into employees- and employer-specific factors, with discontinuous employment, family responsibilities and employer discrimination highlighted as the main barriers to participation in training for parents and especially mothers.

\section{Parent's demand for further training}

The economic theory of the family (Becker, 1981) and bargaining theories (Lundberg and Pollak, 1996) suggest that women generally participate less often in job-related training due to a gendered division of labour. Accordingly, the partner with the higher relative income usually the father - specialises in gainful employment, while women interrupt or reduce their employment after childbirth or change the employer to combine work and family (Steiber and Haas, 2012). In anticipation of lower returns on human capital investments, economic theory predicts that women invest less in their education and training than men, especially in 
employer-specific training (Havet and Sofer, 2008). Conversely, men who anticipate or experience fatherhood are presumed to increase training activities, assuming that they fulfil their role of the main breadwinner (Dieckhoff and Steiber, 2011)

From a sociological perspective, parents do not consciously opt for a specialised division of paid and unpaid work, but because they lack the structural and normative support for an equal division. Especially when the children are young and in a comparatively traditional context, such as West Germany (Zoch, 2021), mothers are more likely to reduce their employment to take on larger shares of unpaid work (Schober and Zoch, 2019). Therefore, mothers mention time constraints and family-work conflicts as the most important reason for not participating in further training (Massing and Gauly, 2017; Burgard, 2012). Fathers today participate more in parental leave and family work than they did several years ago (Schober and Zoch, 2019), so they too state time conflicts, especially with high workloads, as a reason to participate less in training (Massing and Gauly, 2017). However, given longer career breaks, shorter working hours and larger shares of family work, it can be assumed that mothers reduce their training participation more than fathers.

However, most studies show a moderate relevance of individual determinants for training participation, which calls into question the particular importance of human capital theory assumptions (Barry et al., 2020; Dieckhoff and Steiber, 2011; Kaufmann and Widany, 2013). Nevertheless, some studies highlight women's larger share of unpaid work (Burgard, 2012; Massing and Gauly, 2017), increased part-time work (Boll and Bublitz, 2018; Dämmrich et al., 2016), employer or job changes due to childbirth (Burgard, 2012; Havet and Sofer, 2008; Dämmrich et al., 2016) and lower relative earnings (Boll and Bublitz, 2018) as reasons for lower female and maternal training rates. However, without repeated information on individuals' 
training participation, these cross-sectional studies cannot investigate the extent to which the differences are due to childbirth-related changes in paid and unpaid work.

The birth of a child and the associated role changes may also alter work-family preferences, so that parents give less priority to paid work and career development and instead want to spend more time with their family (Stets and Burke, 2000; West and Zimmerman, 1987). Accordingly, mothers, who cannot reconcile their prenatal attitudes with their postnatal employment, are likely to develop more traditional gender ideologies (Schober and Scott, 2012), associated with less job-related training (Dieckhoff and Steiber, 2011; Wotschack, 2019).

Overall, the different theoretical perspectives suggest that childbirth reduces individual demand for job-related training. Given the persistent gender division of paid and unpaid work, this demand reduction should be greater for women than men. Longer career breaks, fewer working hours upon return, and reduced time resources due to increased housework and parental childcare time should explain much of this decline.

\section{Training opportunities and employers' support}

The different supply and access to training opportunities across occupations, sectors and employers account for a much larger part of the training differences than individual demandside aspects (Barry et al., 2020; Burgard, 2012; Dieckhoff and Steiber, 2011; Kaufmann and Widany, 2013). Previous research finds smaller gender training gaps in gender-balanced occupations with larger disadvantages for women in male-dominated occupations (Dieckhoff and Steiber, 2011; Wotschack, 2019). Besides occupation, position and job-tasks, the type and size of the employer increase the likelihood of training participation (Kaufmann and Widany, 2013; Wotschack, 2019), as it is often organised directly or paid for externally in larger 
organisations or the public sector (BMBF 2019; Dämmrich et al., 2016; Dieckhoff and Steiber, 2011). However, based on firm-level data from Germany, Wotschack (2019) finds lower training rates but smaller gender differences in small companies and for contexts supporting women's employment.

Furthermore, previous studies highlight organisational and supervisors' support for jobrelated training (Kaufmann and Widany, 2013). First, employers might perceive family-related employment interruptions and increased absence as a signal of lower productivity and career orientation (Havet and Sofer, 2008). Therefore, longer career breaks and shorter working hours are likely to reduce employees' demand and employers' supply and support for participation in external provision (ibid.), which is in line with empirical findings (Dämmrich et al., 2016). Second, according to theories of status-based discrimination, employers have imperfect information on workers' skills and career ambitions and therefore rely on stereotypes to evaluate their productivity for job placements and promotions (Arrow, 1973; Phelps, 1972). Parents, and mothers in particular, are on average more likely to take career breaks or reduce working hours. With a gendered perception of parenthood and a persistent ideal (male) worker norm, employers may discriminate against them in job placements and, thus, job-related training - regardless of whether they interrupt their work or reduce hours after childbirth (Havet and Sofer, 2008). Experimental evidence highlights motherhood penalties in hiring for Germany (Hipp, 2020), and several studies also find gender and motherhood training gaps after controlling for many individual and job characteristics (Dieckhoff and Steiber, 2011). These studies suggest that the remaining residuals indicate employers' discrimination against women's training participation, particularly in larger, more anonymous firms (Wotschack, 2019). 
While there is ample evidence that employers penalise motherhood, there seem to be career advantages for men, as fathers are often empowered in their role as male breadwinners. Accordingly, men are presumed to increase their human capital investments when experiencing or even anticipating fatherhood, e.g., in salary negotiations or also training participation (Dieckhoff and Steiber, 2011; Burgard, 2012). However, recent research has critically examined the previously proposed fatherhood premiums but found no or only limited evidence for advantages in hiring (Hipp, 2020) or wages (Mari, 2019). Instead, previous studies seem to have overestimated the fatherhood wage premium by not considering that men with steeper wage growth are also more likely to start a family (Rüttenauer and Ludwig, 2020). These findings raise the question of whether fathers receive more support for training and career. Furthermore, men are often older when starting a family and thus more advanced in their careers than mothers. Smaller changes in training behaviour may thus also be due to lower training rates at an older age (BMBF 2019; Blossfeld et al., 2020). Overall, however, when controlling for employment experience, employers' and occupational characteristics, the positive or negative effects of parenthood on training should be smaller for men than for women.

\section{Hypotheses}

Altogether, the few studies focusing explicitly on gender and parenthood differences suggest a training disadvantage for women and especially mothers that is particularly pronounced for job-related training. These differences should be partly related to altered employment participation and increased time for unpaid work as well as changes in employers' support. However, although the findings point to the critical role of childbirth, most studies do not examine a gendered parenthood effect on job-related training. Moreover, no study has 
examined the within-effect of childbirth for altered training behaviour based on panel data. Thus, previous research has not been able to determine whether and to what extent the same respondent changes his or her participation in further job-related training due to childbirth. Therefore, the question remains whether childbirth changes job-related training participation and to what extent the influence of children varies with gender.

Different theoretical approaches such as human capital theory, reduced time availability, altered work-care preferences and employers' discrimination suggest that parents are less likely to participate in job-related training (Hypothesis 1, parenthood penalty). However, time constraints and role conflicts, altered work-care preferences and decreased employers' support seem more likely for mothers than fathers. For this reason, the parenthood training penalties are presumed to be more substantial for mothers than fathers (Hypothesis 2, motherhood vs fatherhood penalty).

\section{Data and analytical strategy}

\section{Data and sample}

By drawing on panel data from the Adult Cohort of the National Educational Panel Study from Germany (NEPS Network, 2021), this analyses compared (1) between-results from linear models using ordinary least squares (pooled linear probability model LPM) with within-person estimates from linear panel models with (2) conventional fixed-effects (FE) and with (3) fixedeffects and individual slopes (FEIS). The NEPS-Adult Cohort offers detailed information on about 12,000 persons of working age, born between the mid-1940s and mid-1980s (Blossfeld and Roßbach, 2019). It is currently the only German panel data set collecting detailed measures of training participation each year, which are particularly well suited for investigating changes in training behaviour due to childbirth. 
The sample used all waves with comparable measures of training participation (wave 212, 2008-2020). It excluded respondents in same-sex couples, with incomplete first education, in higher education or vocational training, in unemployment or retirement, and no employment experience (detailed information is included in online supplementary table A1). Based on observations aged $24-55$ and with complete information on all relevant controls, the final LPM-sample consisted of 43,026 observations (21,316 males and 20,164 females). The FE-sample excluded respondents who participated in job-related training every year or never ( $N_{\text {male }}=15,747$ with 606 births and $N_{\text {female }}=15,110$ with 492 births), to estimate withineffects based on individuals exhibiting change on the dependent variable, thus following the textbook approach for FE and FEIS regression models. ${ }^{2}$ Lastly, FEIS regression models with two slopes required at least four person-years, reducing the sample to $N$ male $=14,396$ and $N$ female $=13,766$ observations. Group-specific observations and distinct individuals are reported in the online supplementary descriptive (A2-A5) and regression tables (A7-A12).

\section{Estimation strategy}

The empirical strategy was implemented in three steps. The first stage examined whether parenthood is generally associated with a lower probability for job-related training, estimating LPM with an interaction for gender and parenthood for the larger pooled sample. Hence, these models most closely resemble research designs from previous cross-sectional studies.

The second stage of this analyses estimated a within-person estimator, examining whether the transition to parenthood is linked to changes in training participation with linear probability models in a FE framework. Unobservable characteristics are likely to influence the outcome (training participation) and main explanatory variable (childbirth), so that a betweenestimator might not accurately estimate the childbirth effect on training participation. The FE 
estimator estimates the relationship between changes in training participation $\boldsymbol{y}_{i t}$ and changes in parenthood $\boldsymbol{i}_{\boldsymbol{i t}}$ ( $0=$ no birth vs $1=$ childbirth within last 12 months), as well as timevariant control variables at the individual-, household- and county-level, denoted as a vector $\boldsymbol{x}_{\boldsymbol{i t}}$ in equation 1 (separately for men and women). $\boldsymbol{\varepsilon}_{\boldsymbol{i t}}$ represents random variation at each point in time and $\boldsymbol{u}_{\boldsymbol{i}}$ captures the effect of time-invariant unobserved variables on the dependent variable.

$$
\text { (1) } y_{i t}=\beta_{1 t}+\beta_{2} i_{i t}+\beta_{3} x_{i t}+u_{i}+\varepsilon_{i t}
$$

By definition, the conventional FE estimator accounts for any constant observed or unobserved heterogeneity and exploits only within-person variation in the dependent and independent variables. Clustered standard errors on the individual and occupational level were estimated to account for the nested data.

To investigate the effect of parenthood over time and a possible anticipation effect of childbirth, the results from the conventional FE estimators with a stepwise impact function i.e. a dummy variable for childbirth - were compared with the results from distributed FE using a continuous impact function. In the latter, $\boldsymbol{i}_{\boldsymbol{i t}}$ denotes an interaction between the parenthood-dummy and the youngest child's age in years centred on the year of childbirth. By restricting the sample to individuals for whom a birth of a child was observed, this withinestimator compares the average training participation in a particular year after childbirth with average training participation in all years before birth.

The third stage of this analyses compared the results from conventional FE and FEIS estimators. As FE requires strict exogeneity of the childbirth-"treatment", soon-to-be-parents and childless respondents are supposed to differ in their absolute training but presumed to experience parallel trends in their work and training trajectories over time. It is thus assumed that training participation of soon-to-be-parents and childless respondents would have 
developed similarly over time if there had been no childbirth. However, in the presence of heterogeneous slopes or growth curves related to training participation, i.e. when the models suffer from a selection on work and training experience into childbirth, this parallel trend assumption is likely to be violated, so that FE-estimates might be biased (Rüttenauer and Ludwig, 2020). ${ }^{3}$ For instance, individuals who have higher career aspirations or more work and training experience could also be those who have a child at an older age or remain childless, while their probability of additional training decreases with age - even without childbirth. Conventional FE would then underestimate the negative effect of childbirth on job-related training. Conversely, FEIS allows for heterogeneity concerning the progress of individual work experience and, thus, associated training trajectories. By accounting for these heterogeneous individual trajectories and thus possible associated patterns of selection into childbirth, FEIS provides an unbiased estimator compared to conventional FE estimators. Unfortunately, to estimate the individual career and training profiles (i.e. two individual slope parameters experience and experience square - and the individual intercept), FEIS requires at least four observations per person. Therefore, efficiency decreases and confidence intervals become larger compared to those in models with conventional FE (Rüttenauer and Ludwig, 2020).

\section{Measures}

Annually all NEPS respondents provide information on whether they participated in any nonformal training in the past 12 months that was job-related, related to personal interests, or both. Therefore, as a dependent variable, this analysis used a binary variable indicating whether the respondent participated in any job-related training versus no participation or participation in courses related to personal interests only (see online supplementary tables A2-A6). 
The main independent variable indicated parenthood in all regression models. Full LPM included the following time-constant control variables (see online supplementary tables A2A3): respondent's educational attainment (university or college degrees vs vocational training and lower qualifications), occupation (KIdB 2010, 2-digit level) and a dummy indicating whether the respondent is living in East Germany. Additionally, LPM and FE regression models included the following time-varying control variables at individual or household level that may influence training participation and/or childbirth (see online supplementary tables A2-A5): respondent's family (partner (ref.), single) and employment status (full-time (ref.), part-time, parental leave), employment experience (in 10 years) and leave take-up (in years), childcare hours on weekdays and current log net household income (in 2015 Euros). Moreover, all models accounted for differences in employer characteristics and thus training opportunities by including information on employer size ( $\leq 20$ employees (ref), 21-200, 201-2000, 2001+, N.A.) and whether the respondent works in the public sector, as self-employed, in a leadership position, or has a fixed-term contract. Additionally, the FE-models accounted for changes in access to further training by including dummy variables for employer or occupational change. To control for changes in regional labour markets and childcare opportunities, all models included the annual unemployment and childcare rate (for 0-3 and 4-6-year-olds) on countylevel provided by the Federal Statistical Office. FEIS models included respondents' labour market experience (in 10 years) as individual slope variables (linear and quadratic terms) to account for heterogeneous career trajectories and possible associated selection into parenthood.

\section{Results}

Descriptives 
About one third of the respondents in the larger sample with all available observations participated in non-formal job-related training, with only minor differences between women (32\%) and men (30\%). The small female training advantage is in line with some of the previous cross-sectional results not distinguishing training rates according to parenthood (e.g., BMBF 2019). However, distinguishing men and women with and without children revealed a pronounced motherhood penalty ( 30 vs $38 \%$ ) compared to training rates that varied less according to men's parenthood status (31 vs $30 \%$ ) (Figure 1, left panel). Furthermore, comparing training participation rates only for parents with observed childbirth (withinsample) revealed statistically significant parenthood penalties for women and men, with a more pronounced disadvantage for mothers (-16 percentage points, Figure 1, right panel) than fathers (-4 percentage points). The descriptive results pointed towards childbirth related changes in job-related training participation, especially for mothers. Moreover, the different parenthood training gaps in the two samples suggested that the small gender disparities in training in previous cross-sectional studies may be due to the fact that larger motherhood training penalties shortly after the birth of a child may have been overlaid by more intensive training participation later in life. Therefore, the particular challenges faced by parents with young children may have been underestimated.

<< Figure 1 here >

The parenthood training penalty for non-formal further education

Figure 2 presents the results for the relationship between parenthood and training participation graphically by plotting the point estimates and their $95 \%$ confidence intervals from adjusted and unadjusted (1) pooled LPM, (2) FE and (3) FEIS regressions. ${ }^{4}$ Coefficients, 
standard errors, number of observations and unique individuals are reported in the online supplementary tables A7-A11.

In line with previous literature, LPM models based on the larger sample suggested a small fatherhood premium of 2 percentage points for men's job-related training participation. ${ }^{5}$ However, using the within-samples, FE (-.11) and FEIS (-.09) models revealed a statistically significant training penalty also for fathers. When accounting for additional changes on the individual, household, employer and occupational level, the coefficient from adjusted within-models decreased and lost statistical significance, suggesting a relatively small change in fathers' job-related training participation. Nevertheless, the contrasting findings from between- and within-estimators suggest that previous cross-sectional studies may have underestimated the challenges that fathers also face in continuing their job-related training shortly after childbirth.

For women, motherhood was associated with a substantial training penalty in all three model specifications. Surprisingly, FE and FEIS estimates confirmed larger and statistically significant motherhood penalties than the between-estimator. With a child, the likelihood of mothers to participate in non-formal training was about 21 (FEIS) to 24 (FE) percentage points lower. When accounting for changes on the individual, household, employer, occupational and regional level, both within-estimates decreased in magnitude and only the FE-estimate remained statistically significant. However, given the smaller FEIS sample and the similar effect sizes of the adjusted FE- and FEIS-estimates, accounting for heterogeneous career and training trajectories in FEIS did not change the pattern of adjusted within-results. The findings therefore mostly support the assumption of a larger training penalty for mothers than fathers. 
$<$ Figure 2 here $>>$

Effect sizes of the time-varying control variables in the linear panel regressions with $\mathrm{FE}$ and FEIS were small and in line with theoretical considerations and previous results from other related studies. Stepwise models revealed that employment experience and leave take-up explained almost half of the fatherhood training penalty (see online supplementary tables A8A11). Although part-time work and (longer) leave take-up are not very common among fathers, changes in employment status, household income and childcare time explained their training penalty at least somewhat. Conversely, changes in the occupation, employer, workplace and regional characteristics did not further explain the remaining fatherhood penalty. Conversely, accounting for employment and leave experience barely explained the motherhood training penalty. Instead, altered employment participation as well as increased childcare time explained almost two-thirds of the gap. Additional analyses also tested a continuous measure of working hours (linear and quadratic terms) and a categorical variable ( $\leq 15$ hours, $16-20$ hours, $21-30$ hours (ref.), 31-35 hours, 36-40 hours and 40 hours or more). The variables showed no significant associations, nor did the patterns of the presented results change. Although higher household income was positively related to job-related training, changes in household income did not substantially explain mothers' decreased training participation. Similarly, changes in employer, workplace characteristics, occupation and regional aspects were of little relevance to explain reduced training participation of mothers.

Overall, comparing the conventional FE estimate with results from pooled LPM illustrated that training penalties even increased when accounting for constant characteristics, such as education, career aspirations, or cognitive ability. These constant characteristics are likely to be correlated with training participation, thus biasing the results of the between- 
estimator. Moreover, compared to the results from conventional FE, adjusted FEIS models accounting for heterogenous individual career and training trajectories showed only slightly smaller parenthood penalties. However, considering the smaller size of the FEIS sample and similar effect sizes of both adjusted within-estimators, accounting for heterogeneous career and training trajectories models did not substantially change the pattern of the results.

\section{Parenthood training penalty over time}

Distributed FE regression models illustrated that for fathers and mothers the average training participation in each year after childbirth was lower than in any year before childbirth (Figure 3, unadjusted; see online supplementary Table A12). Among mothers, training participation declined sharply in the year of childbirth and the subsequent year but increased somewhat after that. However, the findings did not confirm an anticipation effect, i.e., a small reduction in training probability in the year before childbirth $(t=0) .{ }^{6}$ Adjusting for time-varying variables explained all of the observed within-differences for fathers (lower panel). Conversely, for mothers, observed differences remained statistically significant in the first two years after childbirth. Further analyses showed that mothers in West Germany, where childcare capacities remain low and are mostly only offered part-time (Zoch 2020), reduced their training participation more strongly and over more years than in East German (Figure A1 in the online supplementary). Furthermore, mother in West Germany showed a small anticipation effect that was statistically significant at the $5 \%$-level.

$<$ Figure 3 here $>>$

\section{Robustness checks}


To ensure that motherhood penalties were not related to educational disparities and associated labour market inequalities, all models were estimated separately for mothers with at least a college degree and those with lower educational levels (robustness checks are reported in the online supplementary). The FE-results showed only minor educational differences in training penalties whereas FEIS-estimates indicated smaller penalties for mothers with higher education levels (-.11 vs -.03$)$. This is notable because mothers with high levels of education are more likely to realise their less traditional prenatal employment preferences and therefore return to employment earlier and more often full-time (Zoch, 2020). Accordingly, these mothers might be less likely to reduce their demand for training or signal career aspirations more strongly and therefore receive more training opportunities than women with low education levels.

Furthermore, FE models were re-estimated distinguishing males and females according to male-dominated, mixed and female-dominated occupations. However, adjusted models did not reveal substantial occupational differences in parenthood penalties. If at all, parenthood penalties were smaller in female-dominated occupations than in male-dominated and mixed occupations. Although females' effect sizes remained substantial, the results were based on small subsamples, resulting in large confidence intervals and statistically significant estimates only for women in mixed occupations.

To examine the potentially positive role of supportive workplace characteristics, FE models were re-estimated distinguishing between respondents in organisations with or without (a) provision or financing of courses, (b) education planning on a regular basis, (c) a company agreement about further education, or (d) a unit or staff member responsible for organising training. Comparing the results for different employer contexts using separate models or an index on supportive workplace characteristics suggested that mothers working 
in contexts with measures to support job-related training experienced higher prenatal training levels and, thus, somewhat greater training penalties that remained robust when including relevant control variables. Corresponding comparisons showed similar patterns but less substantial penalties for men.

\section{Discussion and Conclusion}

By exploiting large-scale panel data from Germany, this study is the first to examine the question whether the birth of a child is linked to changes in non-formal job-related training participation among working women and men. The results obtained from panel analysis are noteworthy in several respects. The findings from individual FE and FEIS models demonstrate that childbirth reduces the probability of job-related training among parents, thus corresponding to the initial Hypothesis 1, assuming a negative childbirth effect on the participation in job-related training. Although men and women experience a training penalty, the disadvantages of childbirth are more than twice as large for mothers than for fathers. Moreover, the findings highlight that the birth of a child affects the supply and demand aspects influencing training participation differently for men and women. In contrast to earlier findings on fatherhood premiums (Burgard, 2012; Dieckhoff and Steiber, 2011), men also showed fatherhood training penalties. However, these were smaller and mostly related to few changes in employment participation and leave take-up. This might suggest that fathers reduce their demand for further training only temporarily when the child is very young. In sum, results provided less support for a substantial fatherhood training penalty. Conversely, increased childcare time and reduced working hours explained large parts of the motherhood penalty, which corresponds to previous cross-sectional results (Boll and Bublitz, 2018; Dämmrich et al., 2016; Massing and Gauly, 2017). However, in contrast to earlier findings (Burgard, 2012; Dämmrich et al., 2016; Havet and Sofer, 2008), changes in household income, 
employer and occupational characteristics were of little importance in explaining the remaining parenthood penalties for men and women. Moreover, even after adjusting for changes at the individual, household, employer, occupational, and regional levels, the estimated training penalties remained of substantial magnitude, particularly for mothers. The findings therefore also support the second hypothesis, presuming a larger training penalty for mothers than fathers.

Although time-constant and time-varying characteristics explained large parts of the training penalties, the remaining differences suggest that there are further relevant but unobserved factors that significantly reduce parents' participation in job-related training after childbirth, especially for mothers. First, parents could reduce their demand for further training. This could be for various reasons, e.g. because they want to spend more time with their families or because they do not have the time or mental capacity to reconcile family with even more work-related tasks such as further education. Previous research shows that working mothers develop more family-oriented attitudes when they are unable to realise their prenatal attitudes and maternal employment goals due to a lack of support for balancing family and work (Schober and Scott, 2012). With the still inadequate formal childcare coverage levels for the under threes, especially in West Germany and in the form of full-time places (Zoch, 2020), some mothers, particularly those with low education levels, are likely to feel unable to pursue their original career goals and therefore reduce their demand for job-related training.

Second, supervisors and organisations might reduce the availability of training opportunities or their support for training participation of parents, especially mothers. As the statistical models account for changes at the individual, household, employer and occupational levels, the remaining differences could indicate less employer support or 
discrimination against parents and especially mothers, which would confirm previous findings (Hipp, 2020; Dieckhoff and Steiber, 2011). However, without annual information on possible changes in individual career or training aspirations, further workplace characteristics or supervisors support, future studies need to explore this more thoroughly.

Overall, the findings support previous cross-sectional and comparative studies showing a female training disadvantage in several Western countries (Boll and Bublitz, 2018; Dämmrich et al., 2016; Dieckhoff and Steiber, 2011). By examining childbirth-related changes in training participation at the individual level for the first time and separately for men and women, the results suggest that the lower female training rates found in cross-sectional studies are highly likely to be linked to motherhood differences. By considering constant unobserved heterogeneity and a large number of control variables for the individual, household, occupational, employer and regional level, this study highlights the importance of examining a within-estimator, providing a more causal interpretation of the childbirth effect on jobrelated training than previous cross-sectional studies. The results also confirm earlier findings on gender-specific determinants of participation in job-relate training (e.g. Burgard, 2012; Dieckhoff and Steiber, 2011). However, it should be noted: Although a large part of the training gaps can be explained by changes at the individual, employer, occupational and regional levels, these explanations do not diminish the significance of the observed training differences. In particular, the negative impact of maternal childcare time and altered employment reflects the insufficient opportunities for mothers in Germany to reconcile family and work well. In view of this lack of reconciliation, it is not unlikely that working mothers permanently scale back their career ambitions, work part-time, aspire to fewer leadership positions and therefore participate less often in job-related further training over their future career. 
From a broader perspective, the findings extent the evidence of previous studies on the negative effects of childbirth on women's employment and wages (Steiber and Haas, 2012; Hipp, 2020) with longitudinal findings on a training disadvantage upon return to work. Consistent with the literature, gender inequalities in paid and unpaid work also carry over to job-related further training, resulting in larger training penalties for mothers. Assuming that women do not change their training aspirations significantly, the results might further point towards discrimination against mothers with young children. Hence, the findings provide evidence that gendered parenthood effects on job-related training are closely linked to gendered roles and associated labour market inequalities. Based on existing inequalities, the lack of further training is likely to further reduces mothers' already lower changes for promotions and higher earnings, so that inequalities accumulate and result in lower career trajectories, lifetime earnings and, thus, lower wealth accumulation and pensions (e.g. Evertsson, 2004; Havet and Sofer, 2008).

Although this study is the first to estimate a within-estimator, the risk of biased estimates remains due to unobserved characteristics that may correlate with the observables, such as altered aspirations, job tasks or unobserved workplace characteristics. However, by accounting for changes in a large number of individual, household, organizational, occupational and regional characteristics, the results provide a more robust picture than previous cross-sectional studies. It is, however, important to note that, given the small number of observed births, the results should be interpreted with caution. Furthermore, this limitation did not allow to compare within-changes in job-related training according to many other characteristics. Examining educational and workplace inequalities in altered training is therefore an important avenue for future research. This research should carefully investigate direct and indirect mechanisms such as altered career orientation, household bargaining 
processes and potential employer discrimination to further explain the observed motherhood penalties. In addition, it should be explored whether mothers increase their training participation again when the child grows older in order to compensate for reduced training participation shortly after childbirth (Blossfeld et al., 2020). Lastly, possible inequalities within the group of mothers should also be explored, especially with regard to particularly vulnerable groups such as single, low-skilled and low-income mothers.

Despite these limitations, the longitudinal NEPS data provide the great advantage to examine the relationship between childbirth and altered training and the underlying mechanism much more thoroughly than previous cross-sectional studies. In this way, the article provides first longitudinal evidence on the negative effect of childbirth on non-formal job-related training, with larger penalties for mothers than fathers.

\section{References}

Arrow, K. J. (1973) 'The Theory of Discrimination.' in O. Ashenfelter and A. Rees (eds.) Discrimination in Labor Markets, pp. 3-33. Princeton: Princeton University Press.

Barry, M., Gomez, R., Kaufman, B. E., Wilkinson, A. and Zhang, T. (2020) 'Is it 'you' or 'your workplace'? Predictors of job-related training in the Anglo-American world', International Journal of Training and Development 24(3): 173-203.

Becker, G. S. (1981) A treatise on the family. Cambridge, Mass: Harvard University Press.

Blossfeld, H.-P., Kilpi-Jakonen, E. and Vilhena, D. V. de (2020) 'Is there a Matthew effect in adult learning? Results from a cross-national comparison' in J. Schrader, A. Ioannidou and H.-P. Blossfeld (eds.) Monetäre und nicht monetäre Erträge von Weiterbildung, pp. 1-26. Wiesbaden: Springer Fachmedien Wiesbaden.

Blossfeld, H.-P. and Roßbach, H.-G. (2019) Education as a Lifelong Process. Wiesbaden: Springer Fachmedien Wiesbaden.

Boll, C. and Bublitz, E. (2018) 'A Cross-Country Comparison of Gender Differences in Job-Related Training. The Role of Working Hours and the Household Context', British Journal of Industrial Relations 56(3): 503-555.

Burgard, C. (2012) Gender Differences in Further Training Participation. The Role of Individuals, Households and Firms. Essen: Rheinisch-Westfälisches Institut für Wirtschaftsforschung.

Dämmrich, J., Kosyakova, Y. and Blossfeld, H.-P. (2016) 'Gender and job-related non-formal training. A comparison of 20 countries', International Journal of Comparative Sociology 56(6): 433-459. 
Dieckhoff, M. and Steiber, N. (2011) 'A Re-Assessment of Common Theoretical Approaches to Explain Gender Differences in Continuing Training Participation', British Journal of Industrial Relations 49: 135-157.

Evertsson, M. (2004) 'Formal On-the-Job Training. A Gender-Typed Experience and Wage-Related Advantage?', European Sociological Review 20(1): 79-94.

Federal Ministry of Education and Research (BMBF) (2019) Weiterbildungsverhalten in Deutschland 2018. Ergebnisse des Adult Education Survey-AES-Trendbericht. Bonn: Federal Ministry of Education and Research.

Havet, N. and Sofer, C. (2008) 'Why Do Women's Wages Increase So Slowly Throughout Their Career? A Dynamic Model of Statistical Discrimination', Labour 22(2): 291-314.

Hipp, L. (2020) ‘Do Hiring Practices Penalize Women and Benefit Men for Having Children? Experimental Evidence from Germany', European Sociological Review 36(2): 250-264.

Kaufmann, K. and Widany, S. (2013) 'Berufliche Weiterbildung - Gelegenheits- und Teilnahmestrukturen', Zeitschrift für Erziehungswissenschaft 16(1): 29-54, URL (consulted 16 November 2020): http://link.springer.com/10.1007/s11618-013-0338-8.

Lundberg, S. and Pollak, R. A. (1996) 'Bargaining and Distribution in Marriage', Journal of Economic Perspectives 10(4): 139-158.

Mari, G. (2019) 'Is There a Fatherhood Wage Premium? A Reassessment in Societies With Strong Male-Breadwinner Legacies', Journal of Marriage and Family 81(5): 1033-1052.

Massing, N. and Gauly, B. (2017) 'Training Participation and Gender. Analyzing Individual Barriers Across Different Welfare State Regimes', Adult Education Quarterly 67(4): 266-285.

NEPS Network (2021) National Educational Panel Study, Scientific Use File of Starting Cohort Adults. Leibniz Institute for Educational Trajectories (LIfBi). Bamberg, https://doi.org/10.5157/NEPS:SC6:12.1.0.

Phelps, E. S. (1972) 'The Statistical Theory of Racism and Sexism', The American Economic Review 62(4): 659-661.

Rüttenauer, T. and Best, H. (2022) 'Perceived pollution and selective out-migration: revisiting the role of income for environmental inequality', Journal of Ethnic and Migration Studies: 1-21.

Rüttenauer, T. and Ludwig, V. (2020) 'Fixed Effects Individual Slopes: Accounting and Testing for Heterogeneous Effects in Panel Data or Other Multilevel Models', Sociological Methods \& Research: 1-42.

Schober, P. S. and Scott, J. (2012) 'Maternal employment and gender role attitudes: dissonance among British men and women in the transition to parenthood', Work, Employment \& Society 26(3): 514-530.

Schober, P. S. and Zoch, G. (2019) 'Change in the gender division of domestic work after mothers or fathers took leave: exploring alternative explanations', European Societies 21(1): 158-180.

Steiber, N. and Haas, B. (2012) 'Advances in explaining women's employment patterns', SocioEconomic Review 10(2): 343-367.

Stets, J. E. and Burke, P. J. (2000) 'Identity Theory and Social Identity Theory', Social Psychology Quarterly 63(3): 224-237.

West, C. and Zimmerman, D. H. (1987) 'Doing Gender', Gender \& Society 1(2): 125-151.

Wotschack, P. (2019) 'Exploring the (Missing) Gender Training Gap in Germany. The Role of Organizations and Sectors in Continuing Training Participation', Social Politics: International Studies in Gender, State \& Society 26(3): 444-474. 
Zoch, G. (2020) 'Public childcare provision and employment participation of East and West German mothers with different educational backgrounds', Journal of European Social Policy 30(3): 370385.

Zoch, G. (2021) 'Thirty Years after the Fall of the Berlin Wall-Do East and West Germans Still Differ in Their Attitudes to Female Employment and the Division of Housework?', European Sociological Review 37(5): 731-750.

Zoch, G. and Hondralis, I. (2017) 'The Expansion of Low-Cost, State-Subsidized Childcare Availability and Mothers' Return-to-Work Behaviour in East and West Germany', European Sociological Review 33(5): 693-707.

\begin{abstract}
${ }^{1}$ Non-formal further training forms the largest part of adult education in Germany (Federal Ministry of Education and Research (BMBF), 2019). It is distinguished from formal further education with formal certificates (college or BA degree after first education) and from informal further education that is self-organised learning without an instructor. Non-formal further training can either refer to training that is (a) job-related and organised and/or paid for by firms during working hours, (b) to courses that are job-related but organised and/or paid for privately and (c) to training that is related to private interests, e.g. prenatal, health or sports classes.
\end{abstract}

${ }^{2}$ Unfortunately, the conditional logit model does not provide average marginal effects, making the interpretation of the estimated childbirth effects unintuitive. With LPM models in a fixed-effects framework, the effects can be approximated and interpreted as a changed probability - however, no predicted probabilities can be calculated based on the models. An alternative approach would be to rely on Chamberlain's correlated random effects (CRE) probit models, including person-specific means of the covariates as additional regressors, which - according to Rüttenauer and Best (2022) - leads to similar conclusions. However, excluding individuals without change in the dependent variable ensures within-results as close as possible to those from conditional logit models.

${ }^{3}$ These selection mechanisms are particularly strong for women: career-oriented women are more likely to participate in further education but often remain childless or have a child only at a later age when the probability of further training is generally about to decrease. Thus, with increasing employment and training experience, the probability of having a child increases for these women, especially for those with higher educational attainment.

${ }^{4}$ Intervals crossing the vertical 0-line indicate statistically insignificant effects.

${ }^{5}$ Re-estimating the LPM using the smaller within-sample reveals a parenthood training penalty for mothers and fathers. Hence, the results confirm that previously observed gender and parenthood differences might be strongly influenced by groups of respondents with older children, and thus, different parental care demands and employment participation across their later life-course. When children grew older, fathers seem to train more than mothers.

${ }^{6}$ Parents, but especially women, may anticipate future career and family work specialisation due to a child's birth; hence, they may invest less in further education already before parenthood (Dämmrich, Kosyakova, \& Blossfeld, 2016). 


\section{Figures}
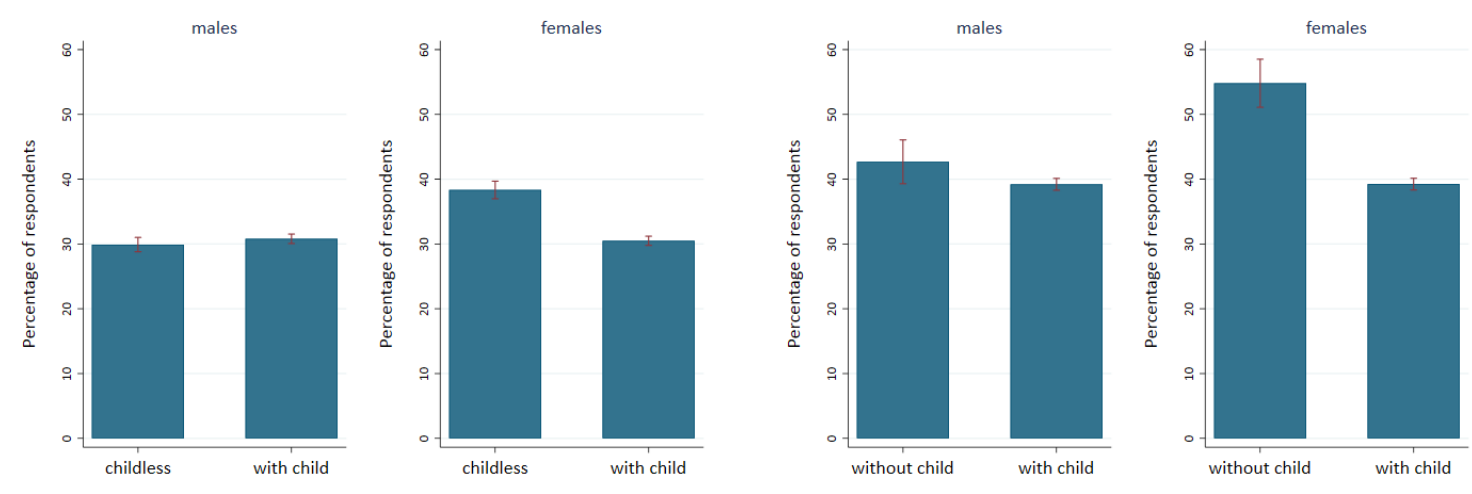

Figure 1. Share of respondents who participated in job-related training over the last 12 months in pooled LPM sample (left panel) and FE-sample (right panel)

Note: 95\% confidence intervals. For details on the number of observations and individuals see online supplementary Tables A2-A6. Source: NEPS:SC6:12.1.0, own calculations, weighted
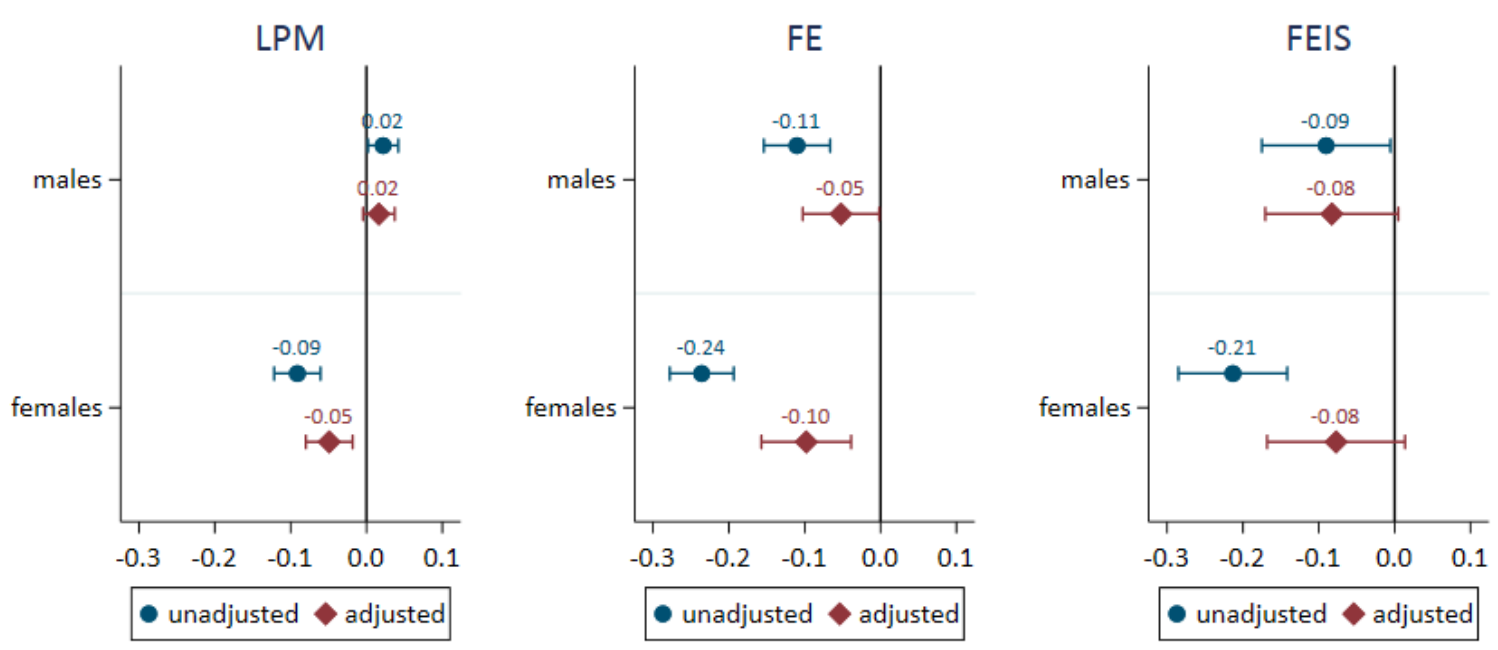

Figure 2. Children and parent's job-related training (results from pooled LPM, FE and FEIS)

Note: LPM based on $\mathrm{N}_{\text {Males }}=21,813$ (4,208 men) and $\mathrm{N}_{\text {Females }}=21,213$ (4,284 women). FE based on $\mathrm{N}_{\text {Males }}=15.747$ (2,529 men) and $\mathrm{N}$ Females $=15.110$ (2,486 women). FEIS based on $N_{\text {Males }}=14.396$ (1,988 men) and $N_{\text {Females }}=13.766$ (1,944 women). $95 \%$ confidence intervals. See online supplementary Tables A7-A11.

Source: NEPS:SC6:12.1.0, own calculations. 

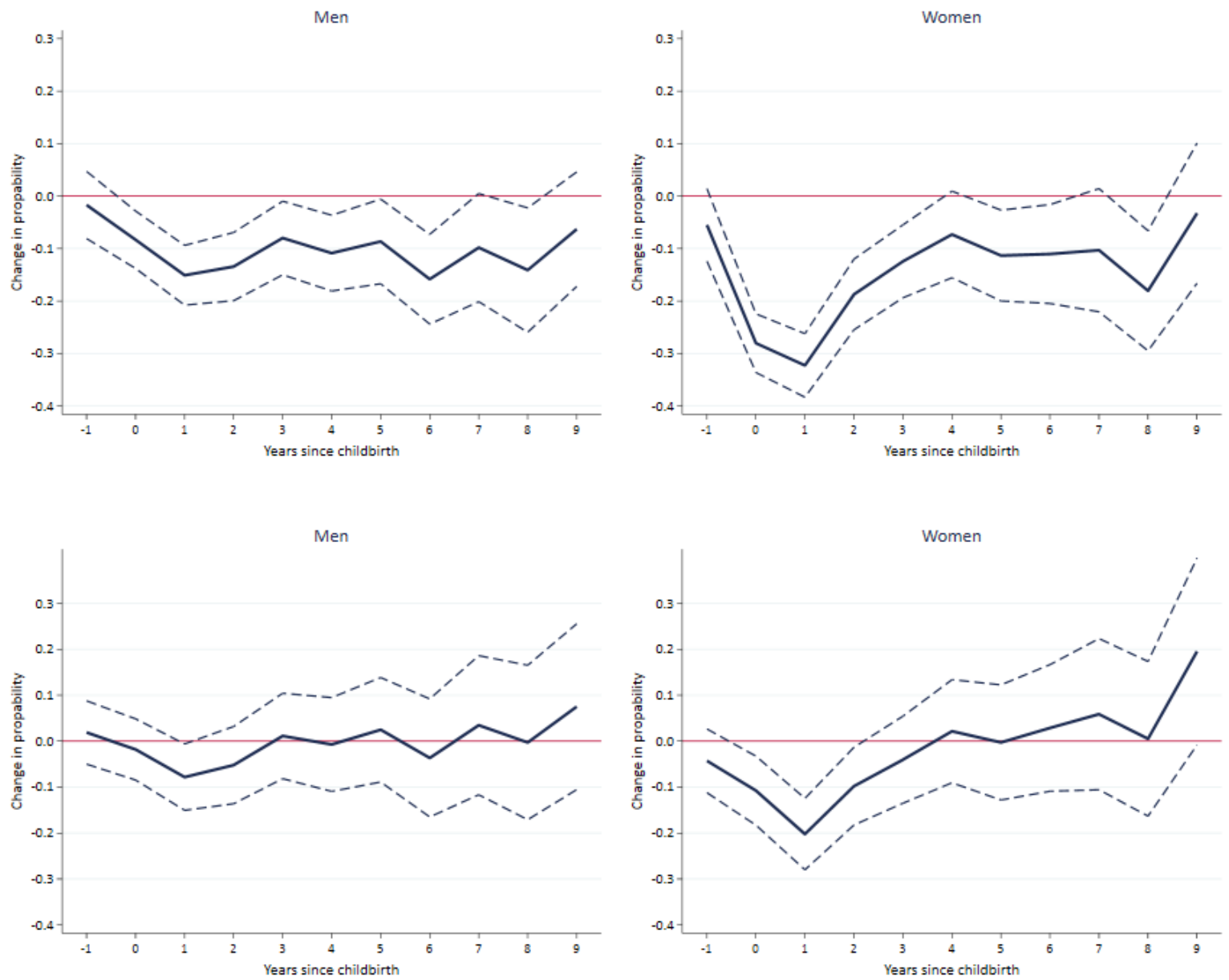

Figure 3. Within-changes in parents' average training participation after childbirth over time from unadjusted (upper panel) and adjusted (lower panel) distributed FE-models

Note: Based on $\mathrm{N}$ Males = 3,996 (606 births) and $\mathrm{N}$ Females = 3,327 (492 births). 95\% confidence intervals. See online supplementary Table A12. Source: NEPS:SC6:12.1.0, own calculations. 


\section{Online Supplementary File}

Table A1. Selection of Estimation Samples

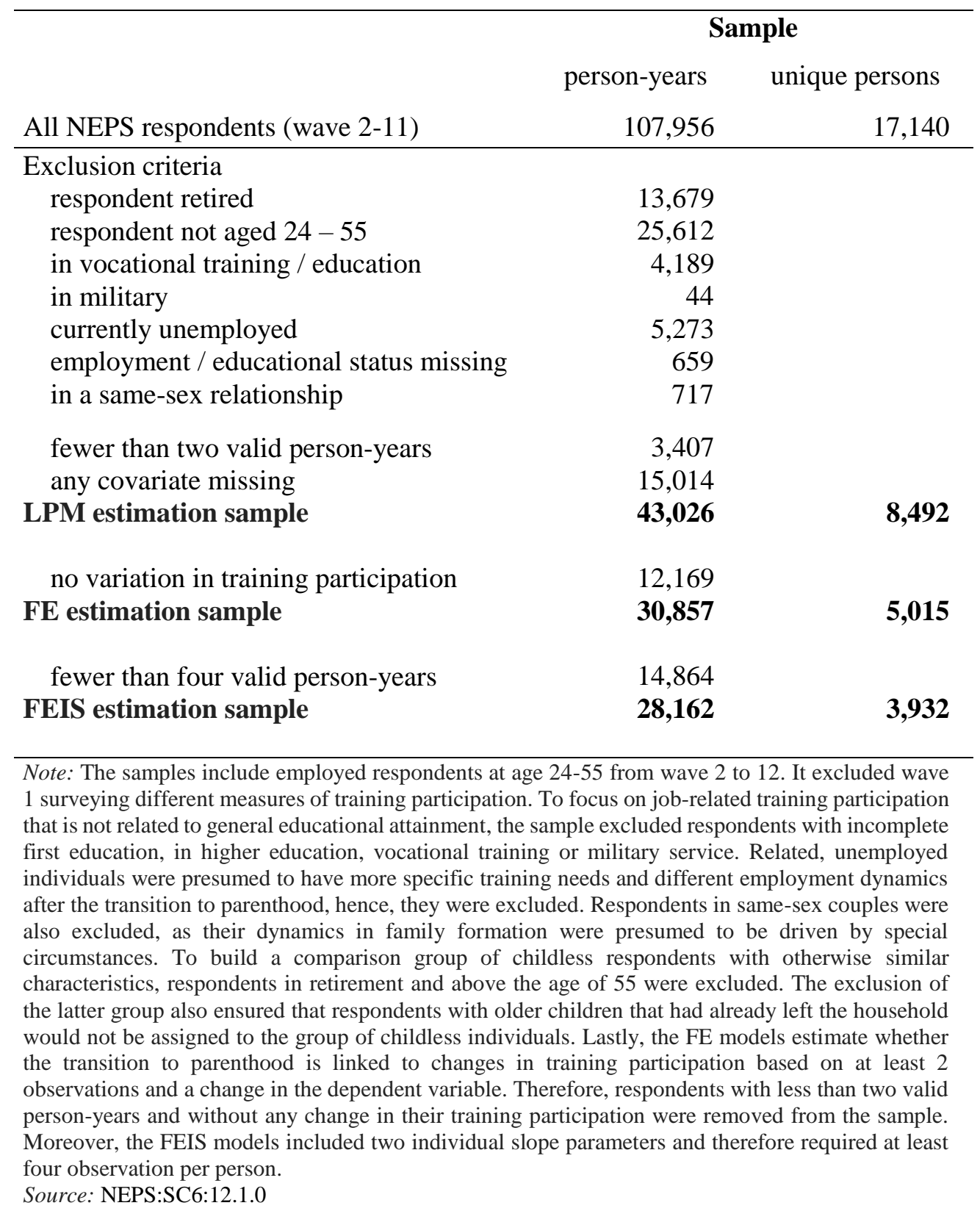


Table A2. Description of variables (LPM and FE-sample, weighted)

\begin{tabular}{|c|c|c|c|c|}
\hline & \multicolumn{2}{|c|}{ LPM Sample } & \multicolumn{2}{|c|}{ FE Sample } \\
\hline & mean $/ \%$ & $\mathrm{sd}$ & mean $/ \%$ & $\mathrm{Sd}$ \\
\hline job-related training & 0.31 & 0.46 & 0.39 & 0.49 \\
\hline female $(d)$ & 0.46 & 0.50 & 0.46 & 0.50 \\
\hline children / childbirth (d) & 0.70 & 0.46 & 0.22 & 0.41 \\
\hline age & 42.02 & 7.82 & 41.55 & 7.52 \\
\hline \multicolumn{5}{|l|}{ education } \\
\hline low (ref.) & 0.25 & 0.43 & 0.19 & 0.39 \\
\hline intermediate & 0.55 & 0.50 & 0.58 & 0.49 \\
\hline high & 0.20 & 0.40 & 0.23 & 0.42 \\
\hline no partner (d) & 0.26 & 0.44 & 0.26 & 0.44 \\
\hline \multicolumn{5}{|l|}{ employment status } \\
\hline full-time (ref.) & 0.60 & 0.49 & 0.63 & 0.48 \\
\hline parental leave & 0.05 & 0.21 & 0.04 & 0.20 \\
\hline part-time & 0.35 & 0.48 & 0.33 & 0.47 \\
\hline childcare time & 2.59 & 4.13 & 2.58 & 4.11 \\
\hline net household income (in $€$ ) & 3554.89 & 2431.65 & 3687.41 & 2531.25 \\
\hline leave experience (in years) & 1.07 & 2.05 & 1.04 & 2.00 \\
\hline \multicolumn{5}{|l|}{ occupation } \\
\hline 1. agriculture/forestry/farming (ref.) & 0.02 & 0.14 & 0.02 & 0.13 \\
\hline 2. production and manufacturing & 0.21 & 0.41 & 0.19 & 0.39 \\
\hline 3. construction/architecture/surveying, & 0.05 & 0.22 & 0.05 & 0.21 \\
\hline 4. nat. sciences/geography/ informatics & 0.05 & 0.23 & 0.06 & 0.24 \\
\hline 5. traffic, logistics, safety and security & 0.11 & 0.31 & 0.09 & 0.29 \\
\hline 6. commercial services/trading/tourism & 0.11 & 0.31 & 0.09 & 0.29 \\
\hline 7. business organisation/accounting/law & 0.22 & 0.42 & 0.25 & 0.43 \\
\hline 8. health care/ social sector/teaching & 0.18 & 0.39 & 0.21 & 0.40 \\
\hline 9. philology/literature/humanities/arts & 0.04 & 0.21 & 0.05 & 0.21 \\
\hline occupational change $(\mathrm{d})$ & 0.08 & 0.27 & 0.08 & 0.27 \\
\hline employer change $(\mathrm{d})$ & 0.14 & 0.35 & 0.14 & 0.34 \\
\hline \multicolumn{5}{|l|}{ firm size } \\
\hline under 20 (ref.) & 0.24 & 0.43 & 0.22 & 0.42 \\
\hline $21-200$ & 0.27 & 0.44 & 0.29 & 0.45 \\
\hline $201-2000$ & 0.18 & 0.38 & 0.21 & 0.41 \\
\hline $2.001+$ & 0.07 & 0.25 & 0.09 & 0.29 \\
\hline NA & 0.24 & 0.43 & 0.19 & 0.39 \\
\hline public sector $(\mathrm{d})$ & 0.21 & 0.41 & 0.24 & 0.43 \\
\hline self-employed (d) & 0.12 & 0.33 & 0.11 & 0.31 \\
\hline leadership position (d) & 0.24 & 0.43 & 0.26 & 0.44 \\
\hline non-permanent contract $(\mathrm{d})$ & 0.20 & 0.40 & 0.22 & 0.41 \\
\hline employment experience (in 10 years) & 1.65 & 0.90 & 1.62 & 0.85 \\
\hline East Germany (d) & 0.20 & 0.40 & 0.20 & 0.40 \\
\hline unemployment rate & 6.44 & 2.87 & 6.32 & 2.85 \\
\hline childcare rate $(0-3)$ & 28.70 & 12.56 & 29.46 & 12.29 \\
\hline childcare rate (4-6) & 92.97 & 3.63 & 92.98 & 3.57 \\
\hline \multicolumn{5}{|l|}{ occupational sex-segregation } \\
\hline male dominated & 0.37 & 0.48 & 0.35 & 0.48 \\
\hline mixed & 0.38 & 0.48 & 0.40 & 0.49 \\
\hline female dominated & 0.26 & 0.44 & 0.25 & 0.43 \\
\hline observations & \multicolumn{2}{|c|}{43026} & \multicolumn{2}{|c|}{30857} \\
\hline individuals & \multicolumn{2}{|c|}{8492} & \multicolumn{2}{|c|}{5015} \\
\hline
\end{tabular}


Table A3. Description of variables (LPM and FE-sample, unweighted)

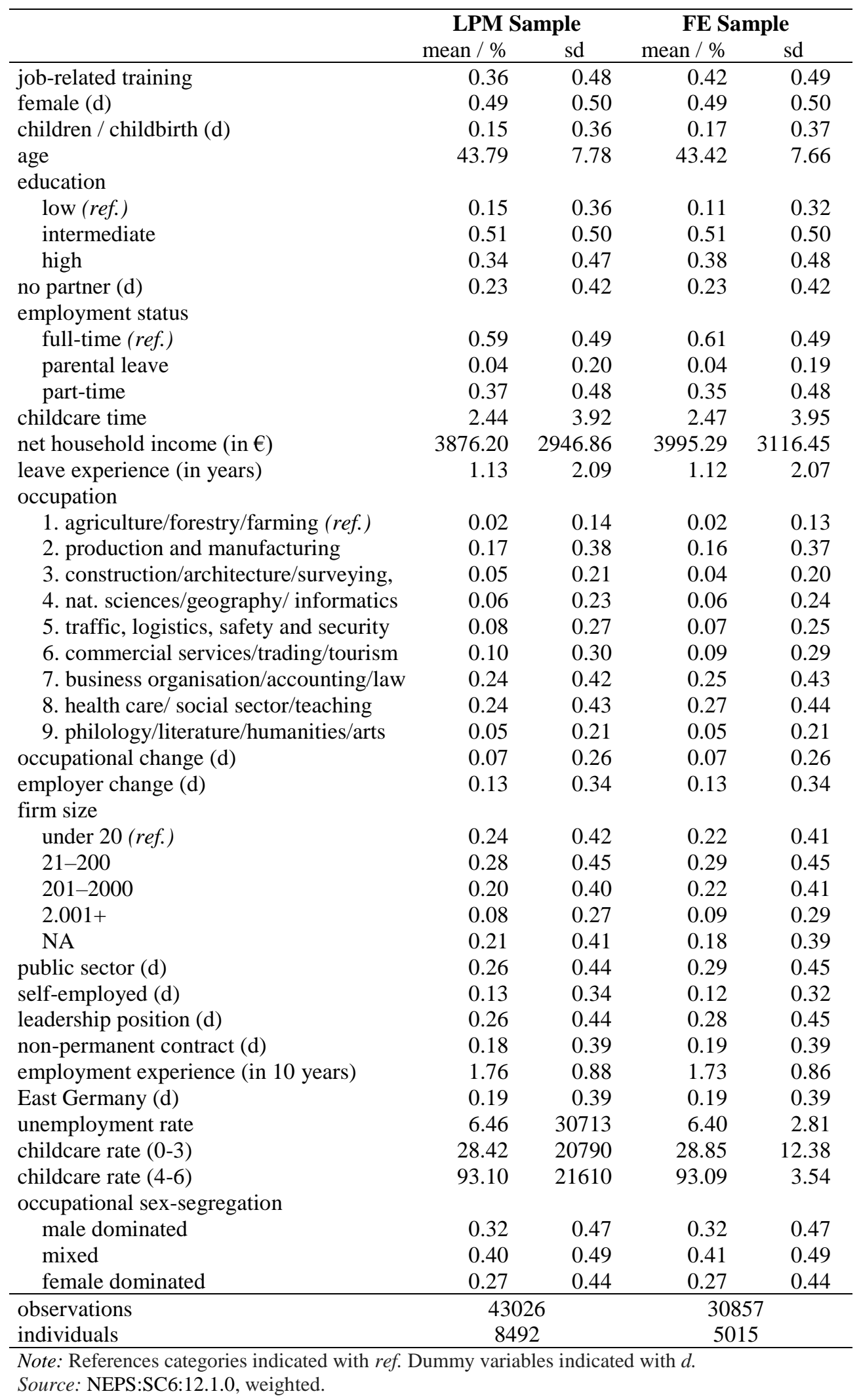


Table A4. Description of variables by childbirth (within sample, weighted)

\begin{tabular}{|c|c|c|c|c|c|c|c|c|}
\hline & \multicolumn{4}{|c|}{ men } & \multicolumn{4}{|c|}{ women } \\
\hline & \multicolumn{2}{|c|}{ childless/before } & \multicolumn{2}{|c|}{ after childbirth } & \multicolumn{2}{|c|}{ childless/before } & \multicolumn{2}{|c|}{ after childbirth } \\
\hline & mean $/ \%$ & $\mathrm{sd}$ & mean $/ \%$ & $\mathrm{sd}$ & mean $/ \%$ & $\mathrm{sd}$ & mean $/ \%$ & $\mathrm{sd}$ \\
\hline job-related training & 0.39 & 0.49 & 0.37 & 0.48 & 0.42 & 0.49 & 0.31 & 0.46 \\
\hline children / childbirth (d) & 0.00 & 0.00 & 1.00 & 0.00 & 0.00 & 0.00 & 1.00 & 0.00 \\
\hline age & 42.28 & 8.01 & 38.68 & 5.87 & 42.59 & 7.62 & 37.72 & 5.16 \\
\hline \multicolumn{9}{|l|}{ education } \\
\hline low (ref.) & 0.26 & 0.44 & 0.22 & 0.41 & 0.13 & 0.34 & 0.11 & 0.31 \\
\hline intermediate & 0.51 & 0.50 & 0.52 & 0.50 & 0.67 & 0.47 & 0.67 & 0.47 \\
\hline high & 0.23 & 0.42 & 0.26 & 0.44 & 0.20 & 0.40 & 0.23 & 0.42 \\
\hline no partner $(\mathrm{d})$ & 0.35 & 0.48 & 0.12 & 0.32 & 0.26 & 0.44 & 0.07 & 0.25 \\
\hline \multicolumn{9}{|l|}{ employment status } \\
\hline full-time (ref.) & 0.84 & 0.37 & 0.77 & 0.42 & 0.46 & 0.50 & 0.15 & 0.35 \\
\hline parental leave & 0.00 & 0.07 & 0.04 & 0.19 & 0.02 & 0.15 & 0.31 & 0.46 \\
\hline part-time & 0.16 & 0.36 & 0.19 & 0.39 & 0.51 & 0.50 & 0.54 & 0.50 \\
\hline childcare time & 0.92 & 1.83 & 3.27 & 3.15 & 2.49 & 3.85 & 9.68 & 6.00 \\
\hline net household income (in $€$ ) & 3649.32 & 2541.80 & 3858.88 & 1839.76 & 3625.00 & 2857.65 & 3743.54 & 1452.83 \\
\hline leave experience (in years) & 0.05 & 0.36 & 0.20 & 0.56 & 2.01 & 2.52 & 2.82 & 2.22 \\
\hline \multicolumn{9}{|l|}{ occupation } \\
\hline 1. agriculture/forestry/farming (ref.) & 0.02 & 0.16 & 0.01 & 0.10 & 0.01 & 0.11 & 0.01 & 0.12 \\
\hline 2. production and manufacturing & 0.28 & 0.45 & 0.33 & 0.47 & 0.06 & 0.24 & $\mathbf{0 . 0 8}$ & 0.27 \\
\hline 3. construction/architecture/surveying, & 0.07 & 0.26 & 0.09 & 0.28 & 0.01 & 0.11 & 0.00 & 0.05 \\
\hline 4. nat. sciences/geography/ informatics & 0.09 & 0.29 & 0.07 & 0.26 & 0.03 & 0.18 & 0.03 & 0.17 \\
\hline 5. traffic, logistics, safety and security & 0.12 & 0.33 & 0.13 & 0.33 & 0.06 & 0.23 & 0.04 & 0.19 \\
\hline 6. commercial services/trading/tourism & 0.08 & 0.27 & 0.06 & 0.23 & 0.13 & 0.33 & 0.11 & 0.31 \\
\hline 7. business organisation/accounting/law & 0.17 & 0.38 & 0.17 & 0.38 & 0.32 & 0.47 & 0.38 & 0.49 \\
\hline 8. health care/ social sector/teaching & 0.11 & 0.31 & 0.11 & 0.32 & 0.33 & 0.47 & 0.30 & 0.46 \\
\hline 9. philology/literature/humanities/arts & 0.05 & 0.22 & 0.04 & 0.19 & 0.05 & 0.21 & 0.04 & 0.21 \\
\hline occupational change $(\mathrm{d})$ & 0.07 & 0.26 & 0.08 & 0.28 & 0.08 & 0.27 & 0.11 & 0.32 \\
\hline employer change $(\mathrm{d})$ & 0.14 & 0.34 & 0.13 & 0.34 & 0.14 & 0.35 & 0.15 & 0.36 \\
\hline \multicolumn{9}{|l|}{ firm size } \\
\hline under 20 (ref.) & 0.21 & 0.41 & 0.18 & 0.38 & 0.26 & 0.44 & 0.23 & 0.42 \\
\hline $21-200$ & 0.29 & 0.45 & 0.27 & 0.44 & 0.30 & 0.46 & 0.23 & 0.42 \\
\hline $201-2000$ & 0.23 & 0.42 & 0.27 & 0.44 & 0.18 & 0.38 & 0.11 & 0.32 \\
\hline $2.001+$ & 0.10 & 0.31 & 0.10 & 0.30 & 0.07 & 0.26 & 0.04 & 0.19 \\
\hline NA & 0.17 & 0.37 & 0.19 & 0.39 & 0.19 & 0.39 & 0.38 & 0.49 \\
\hline public sector $(\mathrm{d})$ & 0.19 & 0.39 & 0.19 & 0.39 & 0.30 & 0.46 & 0.24 & 0.43 \\
\hline self-employed (d) & 0.11 & 0.31 & 0.14 & 0.35 & 0.10 & 0.30 & 0.13 & 0.34 \\
\hline leadership position (d) & 0.32 & 0.47 & 0.33 & 0.47 & 0.19 & 0.40 & 0.17 & 0.38 \\
\hline non-permanent contract $(\mathrm{d})$ & 0.19 & 0.39 & 0.20 & 0.40 & 0.25 & 0.44 & 0.23 & 0.42 \\
\hline employment experience (in 10 years) & 1.77 & 0.92 & 1.42 & 0.65 & 1.65 & 0.86 & 1.09 & 0.56 \\
\hline East Germany (d) & 0.20 & 0.40 & 0.20 & 0.40 & 0.19 & 0.40 & 0.21 & 0.41 \\
\hline unemployment rate & 6.56 & 2.88 & 5.67 & 2.43 & 6.41 & 2.91 & 5.93 & 2.89 \\
\hline childcare rate (0-3) & 28.70 & 12.46 & 31.09 & 12.23 & 28.84 & 12.31 & 30.48 & 11.70 \\
\hline childcare rate (4-6) & 93.13 & 3.55 & 92.91 & 3.56 & 92.77 & 3.64 & 93.32 & 3.29 \\
\hline \multicolumn{9}{|l|}{ occupational sex-segregation } \\
\hline male dominated & 0.56 & 0.50 & 0.56 & 0.50 & 0.10 & 0.30 & 0.14 & 0.35 \\
\hline mixed & 0.35 & 0.48 & 0.36 & 0.48 & 0.44 & 0.50 & 0.43 & 0.49 \\
\hline female dominated & 0.09 & 0.29 & 0.07 & 0.26 & 0.46 & 0.50 & 0.43 & 0.50 \\
\hline observations & 12,9 & & 282 & & 12,7 & & 2,38 & \\
\hline individuals & 2,35 & & 52 & & 2,33 & & 45 & \\
\hline
\end{tabular}

Note: References categories indicated with ref. Dummy variables indicated with $d$. Bold figures indicate significant mean differences between respondents without and with children (t-test, $\mathrm{p}=0.05$ ).

Source: NEPS:SC6:12.1.0, weighted. 
Table A5. Description of variables by childbirth (within sample, unweighted)

\begin{tabular}{|c|c|c|c|c|c|c|c|c|}
\hline & \multicolumn{4}{|c|}{ men } & \multicolumn{4}{|c|}{ women } \\
\hline & \multicolumn{2}{|c|}{ childless/before } & \multicolumn{2}{|c|}{ after childbirth } & \multicolumn{2}{|c|}{ childless/before } & \multicolumn{2}{|c|}{ after childbirth } \\
\hline & mean $/ \%$ & sd & mean $/ \%$ & sd & mean $/ \%$ & sd & mean $/ \%$ & $\mathrm{sd}$ \\
\hline job-related training & 0.41 & 0.49 & 0.40 & 0.49 & 0.45 & 0.50 & 0.34 & 0.48 \\
\hline children / childbirth (d) & 0.00 & 0.00 & 1.00 & 0.00 & 0.00 & 0.00 & 1.00 & 0.00 \\
\hline age & 44.14 & 7.82 & 40.34 & 6.34 & 44.34 & 7.56 & 38.17 & 5.40 \\
\hline \multicolumn{9}{|l|}{ education } \\
\hline low (ref.) & 0.15 & 0.36 & 0.12 & 0.33 & 0.08 & 0.28 & 0.06 & 0.23 \\
\hline intermediate & 0.47 & 0.50 & 0.42 & 0.49 & 0.57 & 0.50 & 0.51 & 0.50 \\
\hline high & 0.38 & 0.49 & 0.46 & 0.50 & 0.35 & 0.48 & 0.43 & 0.50 \\
\hline no partner $(\mathrm{d})$ & 0.28 & 0.45 & 0.09 & 0.29 & 0.23 & 0.42 & 0.07 & 0.26 \\
\hline \multicolumn{9}{|l|}{ employment status } \\
\hline full-time (ref.) & 0.84 & 0.37 & 0.79 & 0.41 & 0.43 & 0.50 & 0.15 & 0.36 \\
\hline parental leave & 0.00 & 0.07 & 0.05 & 0.21 & 0.02 & 0.14 & 0.32 & 0.47 \\
\hline part-time & 0.16 & 0.37 & 0.16 & 0.37 & 0.55 & 0.50 & 0.53 & 0.50 \\
\hline childcare time & 0.99 & 1.72 & 3.03 & 2.85 & 2.48 & 3.70 & 9.74 & 6.18 \\
\hline net household income (in $€$ ) & 4051.01 & 2949.00 & 4349.84 & 2797.58 & 3855.60 & 3524.15 & 4019.08 & 1656.91 \\
\hline leave experience (in years) & 0.06 & 0.37 & 0.24 & 0.59 & 2.12 & 2.58 & 2.59 & 2.13 \\
\hline \multicolumn{9}{|l|}{ occupation } \\
\hline 1. agriculture/forestry/farming (ref.) & 0.02 & 0.15 & 0.01 & 0.12 & 0.01 & 0.11 & 0.01 & 0.11 \\
\hline 2. production and manufacturing & 0.25 & 0.44 & 0.30 & 0.46 & 0.05 & 0.21 & 0.06 & 0.24 \\
\hline 3. construction/architecture/surveying, & 0.07 & 0.26 & 0.07 & 0.25 & 0.02 & 0.13 & 0.01 & 0.09 \\
\hline 4. nat. sciences/geography/ informatics & 0.09 & 0.29 & 0.09 & 0.29 & 0.03 & 0.17 & 0.02 & 0.15 \\
\hline 5. traffic, logistics, safety and security & 0.10 & 0.30 & 0.09 & 0.29 & 0.04 & 0.19 & 0.03 & 0.18 \\
\hline 6. commercial services/trading/tourism & 0.08 & 0.27 & 0.07 & 0.26 & 0.10 & 0.31 & 0.08 & 0.27 \\
\hline 7. business organisation/accounting/law & 0.19 & 0.39 & 0.19 & 0.39 & 0.31 & 0.46 & 0.30 & 0.46 \\
\hline 8. health care/ social sector/teaching & 0.14 & 0.35 & 0.14 & 0.35 & 0.40 & 0.49 & 0.42 & 0.49 \\
\hline 9. philology/literature/humanities/arts & 0.05 & 0.21 & 0.03 & 0.17 & 0.05 & 0.21 & 0.06 & 0.23 \\
\hline occupational change (d) & 0.07 & 0.25 & 0.08 & 0.28 & 0.07 & 0.25 & 0.10 & 0.30 \\
\hline employer change (d) & 0.12 & 0.33 & 0.13 & 0.33 & 0.13 & 0.34 & 0.16 & 0.37 \\
\hline \multicolumn{9}{|l|}{ firm size } \\
\hline under 20 (ref.) & 0.19 & 0.39 & 0.17 & 0.37 & 0.27 & 0.44 & 0.22 & 0.41 \\
\hline $21-200$ & 0.30 & 0.46 & 0.27 & 0.44 & 0.30 & 0.46 & 0.22 & 0.41 \\
\hline $201-2000$ & 0.25 & 0.43 & 0.27 & 0.45 & 0.19 & 0.39 & 0.14 & 0.35 \\
\hline $2.001+$ & 0.12 & 0.32 & 0.13 & 0.34 & 0.06 & 0.24 & 0.05 & 0.21 \\
\hline NA & 0.15 & 0.36 & 0.16 & 0.36 & 0.18 & 0.39 & 0.38 & 0.48 \\
\hline public sector (d) & 0.23 & 0.42 & 0.22 & 0.42 & 0.35 & 0.48 & 0.34 & 0.47 \\
\hline self-employed (d) & 0.12 & 0.33 & 0.12 & 0.32 & 0.11 & 0.32 & 0.11 & 0.32 \\
\hline leadership position (d) & 0.36 & 0.48 & 0.39 & 0.49 & 0.20 & 0.40 & 0.17 & 0.38 \\
\hline non-permanent contract (d) & 0.15 & 0.36 & 0.16 & 0.37 & 0.23 & 0.42 & 0.21 & 0.41 \\
\hline employment experience (in 10 years) & 1.89 & 0.88 & 1.48 & 0.70 & 1.74 & 0.85 & 1.07 & 0.55 \\
\hline East Germany (d) & 0.18 & 0.38 & 0.18 & 0.38 & 0.20 & 0.40 & 0.22 & 0.42 \\
\hline unemployment rate & 6.44 & 2.82 & 5.83 & 2.51 & 6.52 & 2.85 & 6.14 & 2.78 \\
\hline childcare rate $(0-3)$ & 28.16 & 12.41 & 30.43 & 12.02 & 28.70 & 12.48 & 31.51 & 11.60 \\
\hline childcare rate (4-6) & 93.21 & 3.57 & 92.74 & 3.54 & 93.00 & 3.51 & 93.35 & 3.45 \\
\hline \multicolumn{9}{|l|}{ occupational sex-segregation } \\
\hline male dominated & 0.52 & 0.50 & 0.52 & 0.50 & 0.10 & 0.30 & 0.10 & 0.30 \\
\hline mixed & 0.38 & 0.49 & 0.39 & 0.49 & 0.45 & 0.50 & 0.47 & 0.50 \\
\hline female dominated & 0.10 & 0.31 & 0.09 & 0.28 & 0.45 & 0.50 & 0.43 & 0.49 \\
\hline observations & 12 & 925 & 2,8 & & 12,7 & & 2,3 & 86 \\
\hline individuals & 2,3 & & 52 & & 2,3 & & 45 & 52 \\
\hline
\end{tabular}

Note: References categories indicated with ref. Dummy variables indicated with $d$.

Source: NEPS:SC6:12.1.0, weighted. 
Table A6. Average probability to participate in job-related training

\begin{tabular}{|c|c|c|c|c|c|c|c|c|}
\hline & \multicolumn{4}{|c|}{ men } & \multicolumn{4}{|c|}{ women } \\
\hline & \multicolumn{2}{|c|}{ childless/before } & \multicolumn{2}{|c|}{ after childbirth } & \multicolumn{2}{|c|}{ childless/before } & \multicolumn{2}{|c|}{ after childbirth } \\
\hline & mean $/ \%$ & sd & mean $/ \%$ & sd & mean $/ \%$ & sd & mean $/ \%$ & sd \\
\hline education & 0.39 & 0.49 & $\mathbf{0 . 3 7}$ & 0.48 & 0.43 & 0.49 & 0.31 & 0.46 \\
\hline low & 0.35 & 0.48 & 0.32 & 0.47 & 0.40 & 0.49 & 0.25 & 0.43 \\
\hline intermediate & 0.39 & 0.49 & 0.35 & 0.48 & 0.41 & 0.49 & 0.30 & 0.46 \\
\hline high & 0.45 & 0.50 & 0.44 & 0.50 & 0.48 & 0.50 & 0.37 & 0.48 \\
\hline relationship status: single & 0.39 & 0.49 & 0.37 & 0.48 & 0.43 & 0.49 & 0.31 & 0.46 \\
\hline no & 0.40 & 0.49 & 0.37 & 0.48 & 0.43 & 0.49 & 0.30 & 0.46 \\
\hline yes & 0.38 & 0.49 & 0.36 & 0.48 & 0.43 & 0.49 & 0.42 & 0.50 \\
\hline work status & 0.39 & 0.49 & 0.37 & 0.48 & 0.43 & 0.49 & 0.31 & 0.46 \\
\hline full-time & 0.39 & 0.49 & 0.37 & 0.48 & 0.43 & 0.50 & 0.31 & 0.46 \\
\hline parental leave & 0.42 & 0.50 & 0.37 & 0.48 & 0.23 & 0.42 & 0.22 & 0.41 \\
\hline part-time & 0.39 & 0.49 & 0.37 & 0.48 & 0.43 & 0.49 & 0.36 & 0.48 \\
\hline occupation & 0.39 & 0.49 & 0.37 & 0.48 & 0.43 & 0.49 & 0.34 & 0.47 \\
\hline 1. agriculture/forestry/farming (ref.) & 0.34 & 0.47 & 0.48 & 0.51 & 0.34 & 0.48 & 0.17 & 0.39 \\
\hline 2. production and manufacturing & 0.36 & 0.48 & 0.36 & 0.48 & 0.37 & 0.48 & 0.22 & 0.42 \\
\hline 3. construction/architecture/surveying, & 0.34 & 0.47 & 0.26 & 0.44 & 0.35 & 0.48 & 0.76 & 0.44 \\
\hline 4. nat. sciences/geography/ informatics & 0.39 & 0.49 & 0.44 & 0.50 & 0.41 & 0.49 & 0.49 & 0.51 \\
\hline 5. traffic, logistics, safety and security & 0.40 & 0.49 & 0.35 & 0.48 & 0.30 & 0.46 & 0.49 & 0.50 \\
\hline 6. commercial services/trading/tourism & 0.42 & 0.49 & 0.29 & 0.45 & 0.40 & 0.49 & 0.28 & 0.45 \\
\hline 7. business organisation/accounting/law & 0.42 & 0.49 & 0.36 & 0.48 & 0.41 & 0.49 & 0.28 & 0.45 \\
\hline 8. health care/ social sector/teaching & 0.51 & 0.50 & 0.51 & 0.50 & 0.51 & 0.50 & 0.41 & 0.49 \\
\hline 9. philology/literature/humanities/arts & 0.32 & 0.47 & 0.33 & 0.47 & 0.35 & 0.48 & 0.43 & 0.50 \\
\hline occupational change & 0.39 & 0.49 & 0.37 & 0.48 & 0.43 & 0.49 & 0.31 & 0.46 \\
\hline no & 0.39 & 0.49 & 0.36 & 0.48 & 0.42 & 0.49 & 0.31 & 0.46 \\
\hline yes & 0.45 & 0.50 & 0.42 & 0.49 & 0.51 & 0.50 & 0.33 & 0.47 \\
\hline employer change & 0.39 & 0.49 & 0.39 & 0.49 & 0.43 & 0.49 & 0.31 & 0.46 \\
\hline no & 0.39 & 0.49 & 0.39 & 0.49 & 0.42 & 0.49 & 0.30 & 0.46 \\
\hline yes & 0.40 & 0.49 & 0.40 & 0.49 & 0.45 & 0.50 & 0.35 & 0.48 \\
\hline firm size & 0.39 & 0.49 & 0.39 & 0.49 & 0.43 & 0.49 & 0.31 & 0.46 \\
\hline under 20 (ref.) & 0.33 & 0.47 & 0.33 & 0.47 & 0.43 & 0.50 & 0.32 & 0.47 \\
\hline $21-200$ & 0.39 & 0.49 & 0.39 & 0.49 & 0.42 & 0.49 & 0.39 & 0.49 \\
\hline $201-2000$ & 0.42 & 0.49 & 0.42 & 0.49 & 0.45 & 0.50 & 0.33 & 0.47 \\
\hline $2.001+$ & 0.50 & 0.50 & 0.50 & 0.50 & 0.43 & 0.50 & 0.40 & 0.49 \\
\hline NA & 0.38 & 0.49 & 0.38 & 0.49 & 0.40 & 0.49 & 0.24 & 0.42 \\
\hline public sector & 0.39 & 0.49 & 0.37 & 0.48 & 0.43 & 0.49 & 0.31 & 0.46 \\
\hline no & 0.38 & 0.49 & 0.35 & 0.48 & 0.39 & 0.49 & 0.29 & 0.46 \\
\hline yes & 0.45 & 0.50 & 0.43 & 0.50 & 0.50 & 0.50 & 0.35 & 0.48 \\
\hline self-employed & 0.39 & 0.49 & 0.37 & 0.48 & 0.43 & 0.49 & 0.31 & 0.46 \\
\hline no & 0.40 & 0.49 & 0.38 & 0.49 & 0.43 & 0.49 & 0.31 & 0.46 \\
\hline yes & 0.35 & 0.48 & 0.27 & 0.44 & 0.42 & 0.49 & 0.30 & 0.46 \\
\hline leadership position & 0.39 & 0.49 & 0.37 & 0.48 & 0.43 & 0.49 & 0.31 & 0.46 \\
\hline no & 0.38 & 0.49 & 0.38 & 0.48 & 0.42 & 0.49 & 0.31 & 0.46 \\
\hline yes & 0.42 & 0.49 & 0.35 & 0.48 & 0.46 & 0.50 & 0.29 & 0.46 \\
\hline non-permanent contract & 0.39 & 0.49 & 0.37 & 0.48 & 0.43 & 0.49 & 0.31 & 0.46 \\
\hline permanent & 0.39 & 0.49 & 0.38 & 0.48 & 0.43 & 0.49 & 0.31 & 0.46 \\
\hline non-permanent & 0.40 & 0.49 & 0.32 & 0.47 & 0.43 & 0.49 & 0.31 & 0.46 \\
\hline East Germany & 0.39 & 0.49 & 0.37 & 0.48 & $\mathbf{0 . 4 3}$ & 0.49 & 0.31 & 0.46 \\
\hline no & 0.40 & 0.49 & 0.39 & 0.49 & 0.43 & 0.49 & 0.31 & 0.46 \\
\hline yes & 0.37 & 0.48 & 0.28 & 0.45 & 0.42 & 0.49 & 0.32 & 0.47 \\
\hline occupational sex-segregation & 0.39 & 0.49 & 0.37 & 0.48 & 0.43 & 0.49 & 0.34 & 0.47 \\
\hline male dominated & 0.37 & 0.48 & 0.35 & 0.48 & 0.40 & 0.49 & 0.31 & 0.46 \\
\hline mixed & 0.42 & 0.49 & 0.38 & 0.49 & 0.43 & 0.49 & 0.34 & 0.47 \\
\hline female dominated & 0.46 & 0.50 & 0.42 & 0.49 & 0.44 & 0.50 & 0.34 & 0.48 \\
\hline
\end{tabular}

Source: NEPS:SC6:12.1.0, weighted. 
Table A7. Job related training participation - linear probability regression models (males and females, stepwise)

\begin{tabular}{|c|c|c|c|c|c|c|c|c|c|c|c|c|}
\hline \multirow[b]{2}{*}{ female } & \multicolumn{2}{|c|}{ M1 } & \multicolumn{2}{|c|}{ M2 } & \multicolumn{2}{|c|}{ M3 } & \multicolumn{2}{|c|}{ M4 } & \multicolumn{2}{|c|}{ M5 } & \multicolumn{2}{|c|}{ M6 } \\
\hline & $0.098^{* * *}$ & $(0.01)$ & $0.086^{* * *}$ & $(0.01)$ & $0.095^{* * *}$ & $(0.01)$ & $0.069^{* * *}$ & $(0.01)$ & $0.068^{* * *}$ & $(0.01)$ & $0.068^{* * *}$ & $(0.01)$ \\
\hline child(ren) & $0.022^{*}$ & $(0.01)$ & $0.027^{*}$ & $(0.01)$ & $0.022^{*}$ & $(0.01)$ & 0.018 & $(0.01)$ & 0.016 & $(0.01)$ & 0.016 & $(0.01)$ \\
\hline interaction: female \#\# child(ren) & $-0.091^{* * *}$ & $(0.02)$ & $-0.079^{* * *}$ & $(0.02)$ & $-0.050^{* *}$ & $(0.02)$ & $-0.052^{* *}$ & $(0.02)$ & $-0.049^{* *}$ & $(0.02)$ & $-0.049^{* *}$ & $(0.02)$ \\
\hline $\begin{array}{l}\text { education (ref. low) } \\
\text { medium }\end{array}$ & & & $0.095^{* * *}$ & $(0.01)$ & $0.081^{* * *}$ & $(0.01)$ & $0.040^{* * * *}$ & $(0.01)$ & $0.044^{* * *}$ & $(0.01)$ & $0.044^{* * *}$ & $(0.01)$ \\
\hline high & & & $0.190^{* * *}$ & $(0.01)$ & $0.161^{* * * *}$ & $(0.01)$ & $0.080^{* * *}$ & $(0.01)$ & $0.088^{* * *}$ & $(0.01)$ & $0.088^{* * *}$ & $(0.01)$ \\
\hline no partner $(\mathrm{d})$ & & & 0.002 & $(0.01)$ & $0.031^{* * *}$ & $(0.01)$ & $0.020^{*}$ & $(0.01)$ & $0.020^{*}$ & $(0.01)$ & $0.020^{*}$ & $(0.01)$ \\
\hline \multicolumn{13}{|l|}{ employment status (ref. full-time) } \\
\hline parental leave & & & & & $-0.174^{* * *}$ & $(0.01)$ & $-0.143^{* * *}$ & $(0.02)$ & $-0.134^{* * * *}$ & $(0.02)$ & $-0.134^{* * *}$ & $(0.02)$ \\
\hline part-time & & & & & $-0.046^{* * *}$ & $(0.01)$ & $-0.031^{* * *}$ & $(0.01)$ & $-0.031^{* * * *}$ & $(0.01)$ & $-0.031^{* * *}$ & $(0.01)$ \\
\hline childcare time & & & & & $-0.003^{* *}$ & $(0.00)$ & $-0.004^{* * *}$ & $(0.00)$ & $-0.004^{* * *}$ & $(0.00)$ & $-0.004^{* * *}$ & $(0.00)$ \\
\hline net household income (log) & & & & & $0.071^{* * *}$ & $(0.01)$ & $0.041^{* * *}$ & $(0.01)$ & $0.041^{* * *}$ & $(0.01)$ & $0.041^{* * *}$ & $(0.01)$ \\
\hline leave experience in years & & & & & $0.004^{*}$ & $(0.00)$ & 0.004 & $(0.00)$ & 0.004 & $(0.00)$ & 0.004 & $(0.00)$ \\
\hline employer change (d) & & & & & & & 0.006 & $(0.01)$ & 0.005 & $(0.01)$ & 0.005 & $(0.01)$ \\
\hline \multicolumn{13}{|l|}{ firm size $($ ref. $<20)$} \\
\hline $21-200$ & & & & & & & $0.028^{* *}$ & $(0.01)$ & $0.028^{* *}$ & $(0.01)$ & $0.028^{* *}$ & $(0.01)$ \\
\hline $201-2000$ & & & & & & & $0.055^{* * *}$ & $(0.01)$ & $0.056^{* * *}$ & $(0.01)$ & $0.056^{* * *}$ & $(0.01)$ \\
\hline $2.001+$ & & & & & & & $0.090^{* * *}$ & $(0.01)$ & $0.093^{* * *}$ & $(0.01)$ & $0.093^{* * *}$ & $(0.01)$ \\
\hline NA & & & & & & & 0.008 & $(0.01)$ & -0.001 & $(0.01)$ & -0.001 & $(0.01)$ \\
\hline public sector (d) & & & & & & & $0.046^{* * *}$ & $(0.01)$ & $0.044^{* * *}$ & $(0.01)$ & $0.044^{* * *}$ & $(0.01)$ \\
\hline self-employed (d) & & & & & & & -0.005 & $(0.01)$ & -0.004 & $(0.01)$ & -0.004 & $(0.01)$ \\
\hline leadership position (d) & & & & & & & $0.050^{* * *}$ & $(0.01)$ & $0.049^{* * *}$ & $(0.01)$ & $0.049^{* * * *}$ & $(0.01)$ \\
\hline non-permanent contract (d) & & & & & & & -0.001 & $(0.01)$ & 0.001 & $(0.01)$ & 0.001 & $(0.01)$ \\
\hline work experience & & & & & & & 0.017 & $(0.01)$ & 0.018 & $(0.01)$ & 0.018 & $(0.01)$ \\
\hline work experience squared & & & & & & & -0.005 & $(0.00)$ & -0.005 & $(0.00)$ & -0.005 & $(0.00)$ \\
\hline childcare rate $0-3$ & & & & & & & & & $-0.003^{* * *}$ & $(0.00)$ & $-0.003^{* * *}$ & $(0.00)$ \\
\hline childcare rate 4-7 & & & & & & & & & $0.002^{* *}$ & $(0.00)$ & $0.002^{* *}$ & $(0.00)$ \\
\hline unemployment rate & & & & & & & & & -0.001 & $(0.00)$ & -0.001 & $(0.00)$ \\
\hline East Germany & & & & & & & & & $0.058^{* * *}$ & $(0.02)$ & $0.058^{* * *}$ & $(0.02)$ \\
\hline cons & $0.328^{* * * *}$ & $(0.01)$ & $0.211^{* * * *}$ & $(0.01)$ & $-0.342^{* * * *}$ & $(0.06)$ & $-0.187^{*}$ & $(0.09)$ & $-0.348^{* *}$ & $(0.12)$ & $-0.348^{* *}$ & $(0.12)$ \\
\hline Occupation & & & & & & & & & & $(20.12)$ & & 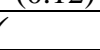 \\
\hline$N$ & \multicolumn{2}{|c|}{43026} & \multicolumn{2}{|c|}{43026} & \multicolumn{2}{|c|}{43026} & \multicolumn{2}{|c|}{43026} & \multicolumn{2}{|c|}{43026} & \multicolumn{2}{|c|}{43026} \\
\hline N_clust & \multicolumn{2}{|c|}{8492} & \multicolumn{2}{|c|}{8492} & \multicolumn{2}{|c|}{8492} & \multicolumn{2}{|c|}{8492} & \multicolumn{2}{|c|}{8492} & \multicolumn{2}{|c|}{8492} \\
\hline r2_a & \multicolumn{2}{|c|}{0.00} & \multicolumn{2}{|c|}{0.02} & \multicolumn{2}{|c|}{0.03} & & & & & & \\
\hline+2 & & & 0. & & & & & & 0 . & & & \\
\hline
\end{tabular}


Table A8. Change in job related training participation - fixed-effects regression models (males, stepwise)

\begin{tabular}{|c|c|c|c|c|c|c|c|c|c|c|c|c|c|c|}
\hline \multirow[b]{2}{*}{ childbirth } & \multicolumn{2}{|c|}{ M1 } & \multicolumn{2}{|c|}{ M2 } & \multicolumn{2}{|c|}{ M3 } & \multicolumn{2}{|c|}{ M4 } & \multicolumn{2}{|c|}{ M5 } & \multicolumn{2}{|c|}{ M6 } & \multicolumn{2}{|c|}{ M7 } \\
\hline & $-0.110^{* * *}$ & $(0.02)$ & $-0.061^{*}$ & $(0.03)$ & $-0.055^{*}$ & $(0.03)$ & $-0.055^{*}$ & $(0.03)$ & $-0.053^{*}$ & $(0.03)$ & $-0.054^{*}$ & $(0.03)$ & $-0.052^{*}$ & $(0.03)$ \\
\hline no partner $(\mathrm{d})$ & & & 0.008 & $(0.02)$ & 0.008 & $(0.02)$ & 0.009 & $(0.02)$ & 0.009 & $(0.02)$ & 0.009 & $(0.02)$ & 0.009 & $(0.02)$ \\
\hline work experience & & & $-0.096^{*}$ & $(0.05)$ & $-0.097^{*}$ & $(0.05)$ & $-0.099^{*}$ & $(0.05)$ & $-0.098^{*}$ & $(0.05)$ & $-0.102^{*}$ & $(0.05)$ & 0.014 & $(0.05)$ \\
\hline work experience squared & & & -0.004 & $(0.01)$ & -0.004 & $(0.01)$ & -0.003 & $(0.01)$ & -0.004 & $(0.01)$ & -0.005 & $(0.01)$ & -0.005 & $(0.01)$ \\
\hline leave experience in years & & & -0.037 & $(0.04)$ & -0.036 & $(0.04)$ & -0.036 & $(0.04)$ & -0.035 & $(0.04)$ & -0.040 & $(0.04)$ & -0.039 & $(0.04)$ \\
\hline employment status (ref. FT) & & & & & $-0.084^{*}$ & $(0.04)$ & $-0.083^{*}$ & $(0.04)$ & -0.080 & $(0.04)$ & -0.043 & $(0.05)$ & -0.034 & $(0.05)$ \\
\hline parental leave & & & & & -0.024 & $(0.02)$ & -0.024 & $(0.02)$ & -0.024 & $(0.02)$ & -0.007 & $(0.03)$ & -0.010 & $(0.03)$ \\
\hline part-time & & & & & & & 0.004 & $(0.02)$ & 0.004 & $(0.02)$ & 0.003 & $(0.02)$ & 0.002 & $(0.02)$ \\
\hline net household income (log) & & & & & & & & & -0.001 & $(0.00)$ & -0.001 & $(0.00)$ & -0.001 & $(0.00)$ \\
\hline childcare time & & & & & & & & & & & $0.078^{* * *}$ & $(0.02)$ & $0.075^{* * *}$ & $(0.02)$ \\
\hline occupational change (d) & & & & & & & & & & & -0.032 & $(0.02)$ & -0.030 & $(0.02)$ \\
\hline employer change (d) & & & & & & & & & & & & & & \\
\hline firm size $($ ref. $<20)$ & & & & & & & & & & & 0.053 & $(0.03)$ & 0.055 & $(0.03)$ \\
\hline $21-200$ & & & & & & & & & & & 0.020 & $(0.03)$ & 0.023 & $(0.03)$ \\
\hline $201-2000$ & & & & & & & & & & & $0.090^{*}$ & $(0.04)$ & $0.092^{*}$ & $(0.04)$ \\
\hline $2.001+$ & & & & & & & & & & & -0.003 & $(0.03)$ & -0.008 & $(0.03)$ \\
\hline NA & & & & & & & & & & & 0.076 & $(0.04)$ & 0.076 & $(0.04)$ \\
\hline public sector $(\mathrm{d})$ & & & & & & & & & & & -0.019 & $(0.03)$ & -0.016 & $(0.03)$ \\
\hline self-employed (d) & & & & & & & & & & & -0.005 & $(0.02)$ & -0.005 & $(0.02)$ \\
\hline leadership position (d) & & & & & & & & & & & 0.032 & $(0.03)$ & 0.034 & $(0.03)$ \\
\hline non-permanent contract (d) & & & & & & & & & & & & & $-0.006^{* * *}$ & $(0.00)$ \\
\hline childcare rate $0-3$ & & & & & & & & & & & & & $0.006^{* *}$ & $(0.00)$ \\
\hline childcare rate $4-7$ & & & & & & & & & & & & & 0.011 & $(0.01)$ \\
\hline unemployment rate & $0.432^{* * *}$ & $(0.00)$ & $0.614^{* * *}$ & $(0.04)$ & $0.620^{* * * *}$ & $(0.04)$ & $0.587^{* * *}$ & $(0.13)$ & $0.587^{* * *}$ & $(0.13)$ & $0.551^{* * *}$ & $(0.13)$ & -0.128 & $(0.24)$ \\
\hline cons & $-0.110^{* * *}$ & $(0.02)$ & $-0.061^{*}$ & $(0.03)$ & $-0.055^{*}$ & $(0.03)$ & $-0.055^{*}$ & $(0.03)$ & $-0.053^{*}$ & $(0.03)$ & $-0.054^{*}$ & $(0.03)$ & $-0.052^{*}$ & $(0.03)$ \\
\hline $\mathrm{N}$ & & & & & & & & & & & & & & \\
\hline N_g & & 29 & & & & 29 & & & & & & & & \\
\hline $\mathrm{F}$ & & & & & & & & 00 & & & & 51 & & 75 \\
\hline r2_o & & 00 & & 00 & & 00 & & 00 & & & & 00 & & \\
\hline r2_w & & 00 & & 01 & & 01 & & 01 & & & & 01 & & \\
\hline $\mathrm{r} 2 \_\mathrm{b}$ & & 00 & & 00 & & 00 & & & & & & 00 & & \\
\hline $\mathrm{p}$ & & 00 & & 00 & & 00 & & 00 & & & & 00 & & \\
\hline
\end{tabular}


Table A9. Change in job related training participation - fixed-effects regression models (females, stepwise)

\begin{tabular}{|c|c|c|c|c|c|c|c|c|c|c|c|c|c|c|}
\hline \multirow[b]{2}{*}{ childbirth } & \multicolumn{2}{|c|}{ M1 } & \multicolumn{2}{|c|}{ M2 } & \multicolumn{2}{|c|}{ M3 } & \multicolumn{2}{|c|}{ M4 } & \multicolumn{2}{|c|}{ M5 } & \multicolumn{2}{|c|}{ M6 } & \multicolumn{2}{|c|}{ M7 } \\
\hline & $-0.236^{* * *}$ & $(0.02)$ & $-0.239^{* * * *}$ & $(0.03)$ & $-0.113^{* * *}$ & $(0.03)$ & $-0.113^{* * *}$ & $(0.03)$ & $-0.092^{* * *}$ & $(0.03)$ & $-0.097^{* *}$ & $(0.03)$ & $-0.098^{* *}$ & $(0.03)$ \\
\hline no partner $(\mathrm{d})$ & & & 0.014 & $(0.02)$ & 0.004 & $(0.02)$ & 0.019 & $(0.03)$ & 0.018 & $(0.03)$ & 0.019 & $(0.03)$ & 0.017 & $(0.03)$ \\
\hline work experience & & & 0.063 & $(0.05)$ & 0.007 & $(0.05)$ & -0.006 & $(0.05)$ & -0.015 & $(0.05)$ & -0.011 & $(0.05)$ & 0.057 & $(0.06)$ \\
\hline work experience squared & & & $-0.028^{*}$ & $(0.01)$ & -0.018 & $(0.01)$ & -0.016 & $(0.01)$ & -0.016 & $(0.01)$ & -0.018 & $(0.01)$ & -0.019 & $(0.01)$ \\
\hline leave experience in years & & & 0.001 & $(0.01)$ & -0.021 & $(0.01)$ & -0.022 & $(0.01)$ & -0.021 & $(0.01)$ & -0.019 & $(0.01)$ & -0.014 & $(0.01)$ \\
\hline \multicolumn{15}{|l|}{ employment status (ref. FT) } \\
\hline part-time & & & & & -0.014 & $(0.02)$ & -0.012 & $(0.02)$ & -0.007 & $(0.02)$ & -0.004 & $(0.02)$ & -0.001 & $(0.02)$ \\
\hline net household income (log) & & & & & & & $0.032^{*}$ & $(0.02)$ & $0.031^{*}$ & $(0.02)$ & $0.031^{*}$ & $(0.02)$ & $0.031^{*}$ & $(0.02)$ \\
\hline childcare time & & & & & & & & & $-0.004^{*}$ & $(0.00)$ & $-0.004^{*}$ & $(0.00)$ & $-0.004^{*}$ & $(0.00)$ \\
\hline occupational change (d) & & & & & & & & & & & $0.072^{* * * *}$ & $(0.02)$ & $0.072^{* * * *}$ & $(0.02)$ \\
\hline employer change (d) & & & & & & & & & & & -0.019 & $(0.02)$ & -0.019 & $(0.02)$ \\
\hline firm size $(r e f .<20)$ & & & & & & & & & & & $0.060^{*}$ & $(0.02)$ & $0.060^{*}$ & $(0.02)$ \\
\hline \multicolumn{15}{|l|}{$21-200$} \\
\hline $201-2000$ & & & & & & & & & & & 0.017 & $(0.03)$ & 0.019 & $(0.03)$ \\
\hline $2.001+$ & & & & & & & & & & & 0.036 & $(0.04)$ & 0.036 & $(0.04)$ \\
\hline NA & & & & & & & & & & & 0.014 & $(0.03)$ & 0.011 & $(0.03)$ \\
\hline public sector (d) & & & & & & & & & & & 0.023 & $(0.03)$ & 0.024 & $(0.03)$ \\
\hline self-employed (d) & & & & & & & & & & & -0.051 & $(0.03)$ & -0.048 & $(0.03)$ \\
\hline leadership position (d) & & & & & & & & & & & -0.021 & $(0.03)$ & -0.023 & $(0.03)$ \\
\hline non-permanent contract (d) & & & & & & & & & & & 0.037 & $(0.02)$ & $0.040^{*}$ & $(0.02)$ \\
\hline childcare rate $0-3$ & & & & & & & & & & & & & $-0.004^{* *}$ & $(0.00)$ \\
\hline childcare rate 4-7 & & & & & & & & & & & & & $0.006^{* *}$ & $(0.00)$ \\
\hline unemployment rate & & & & & & & & & & & & & -0.000 & $(0.01)$ \\
\hline cons & $0.472^{* * *}$ & $(0.00)$ & $0.459^{* * * *}$ & $(0.04)$ & $0.570^{* * *}$ & $(0.05)$ & $0.318^{*}$ & $(0.13)$ & $0.343^{* *}$ & $(0.13)$ & $0.303^{*}$ & $(0.13)$ & -0.236 & $(0.25)$ \\
\hline $\mathrm{N}$ & \multicolumn{2}{|c|}{15110} & \multicolumn{2}{|c|}{15110} & \multicolumn{2}{|c|}{15110} & \multicolumn{2}{|c|}{15110} & \multicolumn{2}{|c|}{15110} & \multicolumn{2}{|c|}{15110} & \multicolumn{2}{|c|}{15110} \\
\hline N_g & \multicolumn{2}{|c|}{2486} & \multicolumn{2}{|c|}{2486} & \multicolumn{2}{|c|}{2486} & \multicolumn{2}{|c|}{2486} & \multicolumn{2}{|c|}{2486} & \multicolumn{2}{|c|}{2486} & \multicolumn{2}{|c|}{2486} \\
\hline r2_o & \multicolumn{2}{|c|}{0.01} & \multicolumn{2}{|c|}{0.01} & & 01 & & 01 & & & & 01 & & \\
\hline r2_w & & 01 & & & & 02 & & 02 & & & & 02 & & \\
\hline $\mathrm{r} 2 \_\mathrm{b}$ & & 01 & & & & 00 & & 01 & & & & 01 & & \\
\hline $\mathrm{F}$ & 11 & & & & & & & & & & & & & \\
\hline 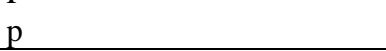 & & 00 & & & & 00 & & 0 & & & & 0 & & \\
\hline
\end{tabular}


Table A10. Change in job related training participation - FEIS regression models (stepwise, males)

\begin{tabular}{|c|c|c|c|c|c|c|c|c|c|c|c|c|c|c|}
\hline \multirow[b]{2}{*}{ childbirth } & \multicolumn{2}{|c|}{ M1 } & \multicolumn{2}{|c|}{ M2 } & \multicolumn{2}{|c|}{ M3 } & \multicolumn{2}{|c|}{ M4 } & \multicolumn{2}{|c|}{ M5 } & \multicolumn{2}{|c|}{ M6 } & \multicolumn{2}{|c|}{ M7 } \\
\hline & $-0.090^{*}$ & $(0.04)$ & $-0.089^{*}$ & $(0.04)$ & -0.077 & $(0.04)$ & -0.074 & $(0.04)$ & -0.075 & $(0.04)$ & -0.080 & $(0.04)$ & -0.083 & $(0.04)$ \\
\hline no partner (d) & & & -0.024 & $(0.03)$ & -0.024 & $(0.03)$ & -0.025 & $(0.03)$ & -0.037 & $(0.03)$ & -0.035 & $(0.04)$ & -0.037 & $(0.03)$ \\
\hline leave experience & & & -0.031 & $(0.08)$ & -0.021 & $(0.08)$ & -0.020 & $(0.08)$ & -0.021 & $(0.08)$ & -0.017 & $(0.08)$ & -0.007 & $(0.08)$ \\
\hline \multicolumn{15}{|l|}{ employment status (ref. FT) } \\
\hline parental leave & & & & & -0.082 & $(0.05)$ & -0.078 & $(0.05)$ & -0.080 & $(0.05)$ & -0.031 & $(0.07)$ & -0.027 & $(0.07)$ \\
\hline part-time & & & & & 0.036 & $(0.05)$ & 0.036 & $(0.05)$ & 0.036 & $(0.05)$ & 0.026 & $(0.05)$ & 0.026 & $(0.05)$ \\
\hline childcare time & & & & & & & -0.001 & $(0.00)$ & -0.002 & $(0.00)$ & -0.001 & $(0.00)$ & -0.001 & $(0.00)$ \\
\hline net household income (log) & & & & & & & & & -0.034 & $(0.02)$ & -0.031 & $(0.02)$ & -0.032 & $(0.02)$ \\
\hline occupational change $(\mathrm{d})$ & & & & & & & & & & & $0.081^{* *}$ & $(0.03)$ & $0.078^{* *}$ & $(0.03)$ \\
\hline employer change (d) & & & & & & & & & & & $-0.040^{*}$ & $(0.02)$ & $-0.040^{*}$ & $(0.02)$ \\
\hline \multicolumn{15}{|l|}{ firm size $(r e f .<20)$} \\
\hline $21-200$ & & & & & & & & & & & 0.078 & $(0.05)$ & 0.083 & $(0.05)$ \\
\hline $201-2000$ & & & & & & & & & & & 0.097 & $(0.06)$ & 0.098 & $(0.06)$ \\
\hline $2.001+$ & & & & & & & & & & & $0.180^{*}$ & $(0.07)$ & $0.176^{*}$ & $(0.07)$ \\
\hline NA & & & & & & & & & & & 0.035 & $(0.06)$ & 0.034 & $(0.06)$ \\
\hline public sector $(\mathrm{d})$ & & & & & & & & & & & 0.062 & $(0.09)$ & 0.065 & $(0.09)$ \\
\hline self-employed (d) & & & & & & & & & & & 0.062 & $(0.07)$ & 0.063 & $(0.07)$ \\
\hline leadership position (d) & & & & & & & & & & & -0.060 & $(0.05)$ & -0.062 & $(0.05)$ \\
\hline non-permanent contract (d) & & & & & & & & & & & 0.048 & $(0.05)$ & 0.049 & $(0.05)$ \\
\hline childcare rate $0-3$ & & & & & & & & & & & & & $-0.007^{* *}$ & $(0.00)$ \\
\hline childcare rate 4-7 & & & & & & & & & & & & & $0.010^{* * * *}$ & $(0.00)$ \\
\hline unemployment rate & & & & & & & & & & & & & 0.016 & $(0.01)$ \\
\hline $\mathrm{N}$ & \multicolumn{2}{|c|}{14396} & \multicolumn{2}{|c|}{14396} & \multicolumn{2}{|c|}{14396} & \multicolumn{2}{|c|}{14396} & \multicolumn{2}{|c|}{14396} & \multicolumn{2}{|c|}{14396} & \multicolumn{2}{|c|}{14396} \\
\hline N_g & \multicolumn{2}{|c|}{1988} & \multirow{2}{*}{\multicolumn{2}{|c|}{1988}} & \multirow{2}{*}{\multicolumn{2}{|c|}{1988}} & \multirow{2}{*}{\multicolumn{2}{|c|}{1988}} & \multirow{2}{*}{\multicolumn{2}{|c|}{$\begin{array}{l}1988 \\
0.00\end{array}$}} & \multicolumn{2}{|c|}{1988} & \multicolumn{2}{|c|}{1988} \\
\hline $\mathrm{r} 2 \_\mathrm{w}$ & \multicolumn{2}{|c|}{0.00} & & & & & & & & & & & 0. & \\
\hline
\end{tabular}

Note: Standard errors in parentheses. Source: NEPS:SC6:12.1.0, own calculations

${ }^{*} p<0.05,{ }^{* *} p<0.01,{ }^{* * *} p<0.001$ 
Table A11. Change in job related training participation - FEIS regression models (stepwise, females)

\begin{tabular}{|c|c|c|c|c|c|c|c|c|c|c|c|c|c|c|}
\hline \multirow[b]{2}{*}{ childbirth } & \multicolumn{2}{|c|}{ M1 } & \multicolumn{2}{|c|}{ M2 } & \multicolumn{2}{|c|}{ M3 } & \multicolumn{2}{|c|}{ M4 } & \multicolumn{2}{|c|}{ M5 } & \multicolumn{2}{|c|}{ M6 } & \multicolumn{2}{|c|}{ M7 } \\
\hline & $-0.213^{* * *}$ & $(0.04)$ & $-0.208^{* * * *}$ & $(0.04)$ & $-0.096^{*}$ & $(0.04)$ & -0.069 & $(0.05)$ & -0.069 & $(0.05)$ & -0.072 & $(0.05)$ & -0.077 & $(0.05)$ \\
\hline no partner (d) & & & -0.018 & $(0.04)$ & -0.023 & $(0.04)$ & -0.022 & $(0.04)$ & -0.010 & $(0.05)$ & -0.009 & $(0.05)$ & -0.011 & $(0.05)$ \\
\hline leave experience & & & -0.009 & $(0.02)$ & -0.019 & $(0.02)$ & -0.019 & $(0.02)$ & -0.020 & $(0.02)$ & -0.020 & $(0.02)$ & -0.021 & $(0.02)$ \\
\hline \multirow{2}{*}{\multicolumn{15}{|c|}{ employment status (ref. FT) }} \\
\hline & & & & & $-0.169^{* * *}$ & $(0.04)$ & $-0.147^{* * *}$ & $(0.04)$ & $-0.144^{* * *}$ & $(0.04)$ & $-0.116^{*}$ & $(0.05)$ & $-0.119^{*}$ & $(0.05)$ \\
\hline part-time & & & & & -0.016 & $(0.04)$ & -0.011 & $(0.04)$ & -0.010 & $(0.03)$ & -0.007 & $(0.04)$ & -0.008 & $(0.04)$ \\
\hline childcare time & & & & & & & -0.004 & $(0.00)$ & -0.004 & $(0.00)$ & -0.004 & $(0.00)$ & -0.004 & $(0.00)$ \\
\hline net household income (log) & & & & & & & & & 0.025 & $(0.02)$ & 0.026 & $(0.02)$ & 0.025 & $(0.02)$ \\
\hline occupational change (d) & & & & & & & & & & & $0.049^{*}$ & $(0.02)$ & 0.048 & $(0.02)$ \\
\hline employer change (d) & & & & & & & & & & & -0.022 & $(0.02)$ & -0.022 & $(0.02)$ \\
\hline \multicolumn{15}{|l|}{ firm size $($ ref. $<20)$} \\
\hline $21-200$ & & & & & & & & & & & -0.010 & $(0.04)$ & -0.012 & $(0.04)$ \\
\hline 201-2000 & & & & & & & & & & & 0.005 & $(0.05)$ & 0.004 & $(0.05)$ \\
\hline $2.001+$ & & & & & & & & & & & 0.096 & $(0.07)$ & 0.094 & $(0.07)$ \\
\hline NA & & & & & & & & & & & -0.021 & $(0.04)$ & -0.021 & $(0.04)$ \\
\hline public sector (d) & & & & & & & & & & & 0.011 & $(0.05)$ & 0.011 & $(0.05)$ \\
\hline self-employed (d) & & & & & & & & & & & -0.029 & $(0.05)$ & -0.030 & $(0.05)$ \\
\hline leadership position (d) & & & & & & & & & & & -0.010 & $(0.05)$ & -0.009 & $(0.05)$ \\
\hline non-permanent contract $(\mathrm{d})$ & & & & & & & & & & & 0.016 & $(0.04)$ & 0.016 & $(0.04)$ \\
\hline childcare rate $0-3$ & & & & & & & & & & & & & 0.002 & $(0.00)$ \\
\hline childcare rate $4-7$ & & & & & & & & & & & & & $0.008^{* *}$ & $(0.00)$ \\
\hline unemployment rate & & & & & & & & & & & & & -0.005 & $(0.01)$ \\
\hline $\mathrm{N}$ & \multicolumn{2}{|c|}{13766} & \multicolumn{2}{|c|}{13766} & \multicolumn{2}{|c|}{13766} & \multicolumn{2}{|c|}{13766} & \multicolumn{2}{|c|}{13766} & \multicolumn{2}{|c|}{13766} & \multicolumn{2}{|c|}{13766} \\
\hline N_g & \multicolumn{2}{|c|}{1944} & \multirow{2}{*}{\multicolumn{2}{|c|}{1944}} & \multirow{2}{*}{\multicolumn{2}{|c|}{1944}} & \multirow{2}{*}{\multicolumn{2}{|c|}{$\begin{array}{l}1944 \\
0.01\end{array}$}} & \multirow{2}{*}{\multicolumn{2}{|c|}{1944}} & \multirow{2}{*}{\multicolumn{2}{|c|}{1944}} & \multirow{2}{*}{\multicolumn{2}{|c|}{1944}} \\
\hline r2_w & & & & & & & & & & & & & 0.01 & \\
\hline
\end{tabular}

Note: Standard errors in parentheses. Source: NEPS:SC6:12.1.0, own calculations

${ }^{*} p<0.05,{ }^{* *} p<0.01,{ }^{* * *} p<0.001$ 
Table A12. Change in job related training participation over time - Distributed fixed-effects regression models with anticipation effect

\begin{tabular}{|c|c|c|c|c|c|c|c|c|}
\hline \multirow{3}{*}{ year before / after childbirth } & \multicolumn{4}{|c|}{ Men } & \multicolumn{4}{|c|}{ Women } \\
\hline & \multicolumn{2}{|c|}{ M1 } & \multicolumn{2}{|c|}{ M2 } & \multicolumn{2}{|c|}{ M1 } & \multicolumn{2}{|c|}{ M2 } \\
\hline & & & & & & & & \\
\hline - 1 year before childbirth & -0.02 & $(0.03)$ & 0.02 & $(0.04)$ & -0.05 & $(0.04)$ & -0.04 & $(0.04)$ \\
\hline 0 year of childbirth & $-0.08^{* *}$ & $(0.03)$ & -0.02 & $(0.03)$ & $-0.28^{* * *}$ & $(0.03)$ & $-0.11^{* * *}$ & $(0.04)$ \\
\hline 1 year after & $-0.15^{* * *}$ & $(0.03)$ & $-0.08^{*}$ & $(0.04)$ & $-0.32^{* * *}$ & $(0.03)$ & $-0.20^{* * * *}$ & $(0.04)$ \\
\hline 2 year after & $-0.13^{* * *}$ & $(0.03)$ & -0.05 & $(0.04)$ & $-0.19^{* * *}$ & $(0.03)$ & $-0.10^{*}$ & $(0.04)$ \\
\hline 3 year after & $-0.08^{*}$ & $(0.04)$ & 0.01 & $(0.05)$ & $-0.12^{* * *}$ & $(0.04)$ & -0.04 & $(0.05)$ \\
\hline 4 year after & $-0.11^{* * *}$ & $(0.04)$ & -0.01 & $(0.05)$ & -0.07 & $(0.04)$ & 0.02 & $(0.06)$ \\
\hline 5 year after & $-0.09^{*}$ & $(0.04)$ & 0.02 & $(0.06)$ & $-0.11^{*}$ & $(0.04)$ & -0.00 & $(0.06)$ \\
\hline 6 year after & $-0.16^{* * *}$ & $(0.04)$ & -0.04 & $(0.07)$ & $-0.11^{*}$ & $(0.05)$ & 0.03 & $(0.07)$ \\
\hline 7 year after & -0.10 & $(0.05)$ & 0.03 & $(0.08)$ & -0.10 & $(0.06)$ & 0.06 & $(0.08)$ \\
\hline 8 year after & $-0.14^{*}$ & $(0.06)$ & -0.00 & $(0.09)$ & $-0.18^{* *}$ & $(0.06)$ & 0.01 & $(0.09)$ \\
\hline 9 year after & -0.06 & $(0.06)$ & 0.08 & $(0.09)$ & -0.03 & $(0.07)$ & 0.20 & $(0.10)$ \\
\hline no partner $(\mathrm{d})$ & & & 0.05 & $(0.04)$ & & & 0.06 & $(0.05)$ \\
\hline \multicolumn{9}{|l|}{ employment status (ref. FT) } \\
\hline parental leave & & & 0.02 & $(0.06)$ & & & -0.09 & $(0.05)$ \\
\hline part-time & & & 0.02 & $(0.05)$ & & & -0.00 & $(0.03)$ \\
\hline childcare time & & & -0.00 & $(0.00)$ & & & $-0.00^{*}$ & $(0.00)$ \\
\hline leave experience & & & -0.03 & $(0.05)$ & & & -0.02 & $(0.01)$ \\
\hline net household income $(\log )$ & & & 0.04 & $(0.04)$ & & & $0.13^{* * * *}$ & $(0.04)$ \\
\hline occupational change $(\mathrm{d})$ & & & 0.04 & $(0.04)$ & & & 0.06 & $(0.03)$ \\
\hline employer change (d) & & & -0.02 & $(0.03)$ & & & -0.02 & $(0.03)$ \\
\hline \multicolumn{9}{|l|}{ firm size $($ ref. <20) } \\
\hline $21-200$ & & & 0.08 & $(0.05)$ & & & -0.00 & $(0.04)$ \\
\hline $201-2000$ & & & 0.06 & $(0.05)$ & & & -0.05 & $(0.05)$ \\
\hline $2.001+$ & & & $0.13^{*}$ & $(0.06)$ & & & 0.09 & $(0.06)$ \\
\hline NA & & & 0.01 & $(0.06)$ & & & -0.05 & $(0.04)$ \\
\hline public sector (d) & & & 0.04 & $(0.07)$ & & & 0.01 & $(0.04)$ \\
\hline self-employed (d) & & & -0.01 & $(0.06)$ & & & -0.09 & $(0.06)$ \\
\hline leadership position (d) & & & -0.01 & $(0.04)$ & & & -0.01 & $(0.04)$ \\
\hline non-permanent contract (d) & & & -0.02 & $(0.04)$ & & & -0.03 & $(0.03)$ \\
\hline work experience & & & -0.12 & $(0.10)$ & & & 0.14 & $(0.12)$ \\
\hline work experience squared & & & 0.03 & $(0.03)$ & & & $-0.13^{* * *}$ & $(0.05)$ \\
\hline childcare rate $0-3$ & & & $-0.01^{*}$ & $(0.00)$ & & & $-0.01^{*}$ & $(0.00)$ \\
\hline childcare rate 4-7 & & & $0.01^{*}$ & $(0.00)$ & & & $0.01^{*}$ & $(0.00)$ \\
\hline unemployment rate & & & 0.01 & $(0.01)$ & & & -0.01 & $(0.01)$ \\
\hline _cons & $0.50^{* * *}$ & $(0.02)$ & -0.48 & $(0.46)$ & $0.53^{* * *}$ & $(0.02)$ & $-1.11^{*}$ & $(0.48)$ \\
\hline $\bar{N}$ & \multicolumn{2}{|c|}{3996} & \multicolumn{2}{|c|}{3996} & \multicolumn{2}{|c|}{3327} & \multicolumn{2}{|c|}{3327} \\
\hline N_g & \multicolumn{2}{|c|}{528} & \multicolumn{2}{|c|}{528} & \multicolumn{2}{|c|}{452} & \multicolumn{2}{|c|}{452} \\
\hline $\mathrm{F}$ & \multicolumn{2}{|c|}{3.40} & \multicolumn{2}{|c|}{2.21} & \multicolumn{2}{|c|}{15.93} & \multicolumn{2}{|c|}{10.93} \\
\hline r2_o & \multicolumn{2}{|c|}{0.01} & & & 0. & & 0. & \\
\hline r2_w & 0.0 & & & & 0. & & 0. & \\
\hline $\mathrm{r} 2 \_\mathrm{b}$ & 0.0 & & & & $0 .($ & & 0. & \\
\hline $\mathrm{p}$ & 0.0 & & & & 0. & & 0. & \\
\hline
\end{tabular}

Note: Standard errors in parentheses. Source: NEPS:SC6:12.1.0, own calculations

${ }^{*} p<0.05,{ }^{* *} p<0.01,{ }^{* * * *} p<0.001$ 

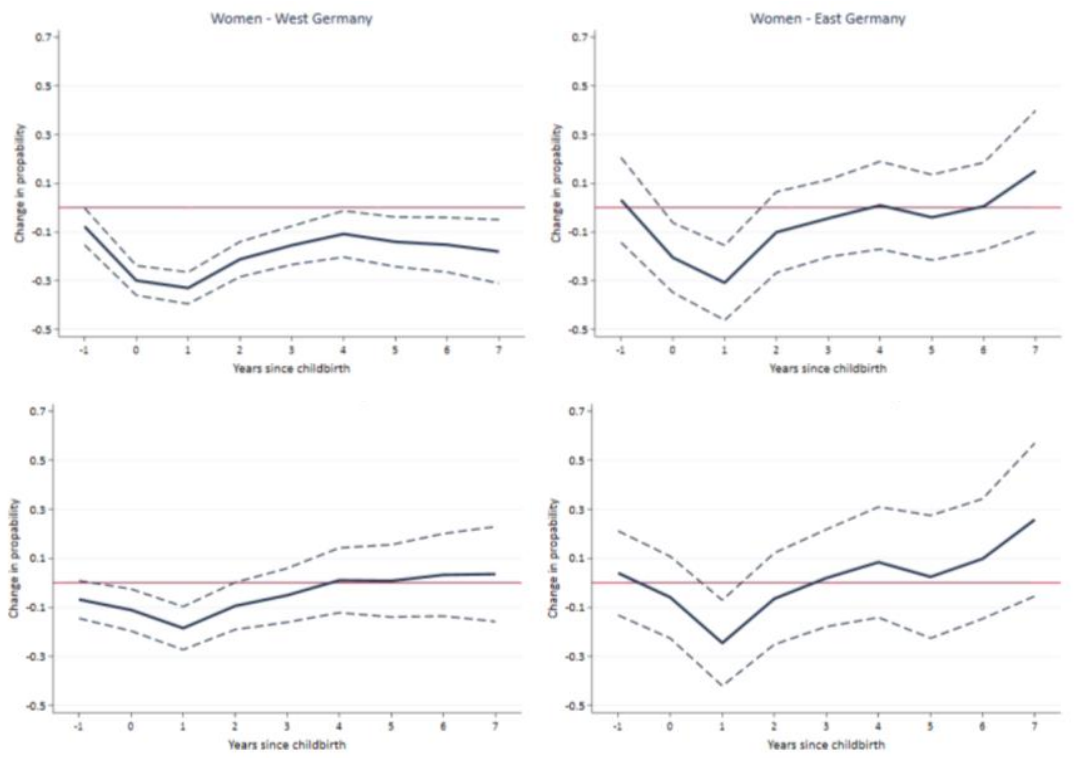

Figure A1. Within-changes in West and East German mothers' average training participation after childbirth over time from unadjusted (upper panel) and adjusted (lower panel) distributed FE-models

Note: Based on $\mathrm{N}_{\text {West }}=2,508$ and $\mathrm{N}_{\text {Females }}=626.95 \%$ confidence intervals.

Source: NEPS:SC6:12.1.0, own calculations. 


\section{Robustness Checks}

\section{Check 1: Educational disparities in the motherhood training penalty}

To ensure that the motherhood penalties so far observed were not related to educational disparities and associated labour market inequalities, all models were re-estimated for separate educational groups. As the sample size contained too few women with low educational attainment, a distinction was only made between women with a university or college degree (high education) and those with lower educational levels (low education). Results from separate LPM, FE and FEIS regressions showed only small educational differences in the observed motherhood training penalties (see Figure A2). If at all, mothers with lower levels educational levels showed larger penalties (-.08 in LPM, -.24 in FE and -.25 in FEIS) than those with higher educational attainment (-.07 in LPM, -.23 in FE and -.16 in FEIS) only in the unadjusted FEIS models. When accounting for heterogeneous career trajectories and the full set of controls in the panel models, estimates decreased and lost statistical significance especially for mothers with higher education levels (-.09 in FE and -.03 in FEIS), particularly for the smaller FEIS sample. Nevertheless, effect sizes remained substantial, with larger effect sizes for mothers with lower educational levels (-.11 in FE and FEIS). Similar education-specific within-models showed no fatherhood penalties.
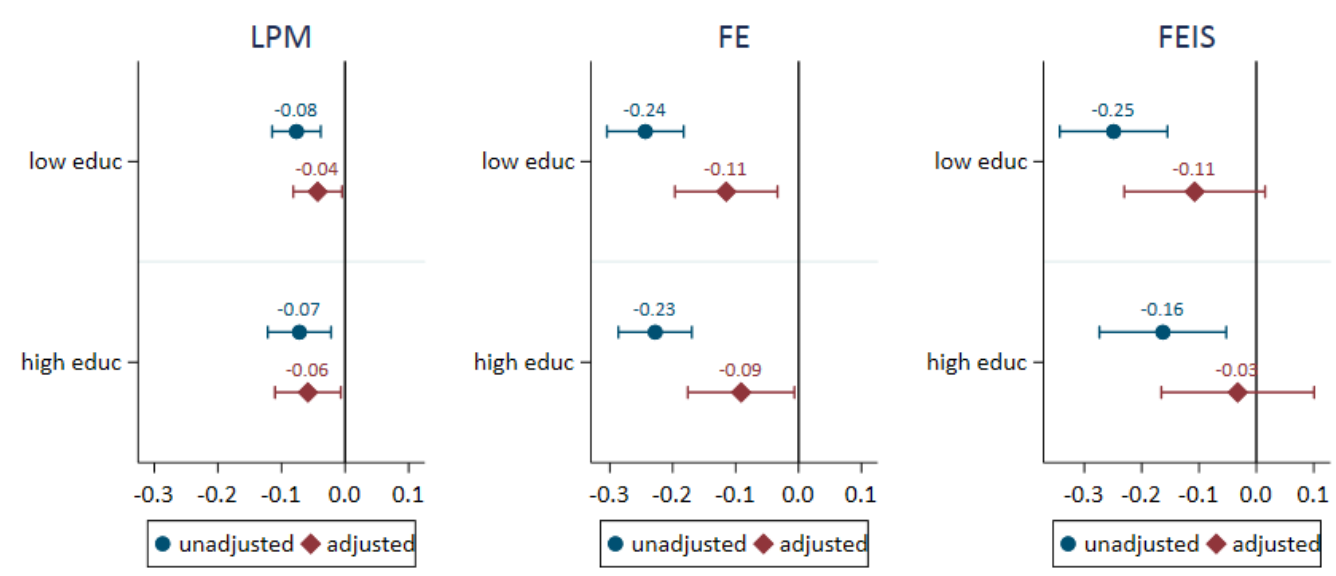

Figure A2. Motherhood-differences in the participation in job-related training across educational backgrounds (pooled LPM, FE, FEIS) 
Table A13. Change in job related training participation by education

\begin{tabular}{|c|c|c|c|c|c|c|c|c|c|c|c|c|}
\hline & \multicolumn{4}{|c|}{ LPM } & \multicolumn{4}{|c|}{ FE (mothers) } & \multicolumn{4}{|c|}{ FEIS (mothers) } \\
\hline & \multicolumn{2}{|c|}{ education low } & \multicolumn{2}{|c|}{ education high } & \multicolumn{2}{|c|}{ education low } & \multicolumn{6}{|c|}{ education high education low education high } \\
\hline & M1 & $\mathrm{M} 2$ & M1 & M2 & M1 & M2 & M1 & M2 & M1 & M2 & M1 & M2 \\
\hline female & $0.083^{* * * *}$ & $0.038^{*}$ & $0.107^{* * *}$ & $0.111^{* * * *}$ & & & & & & & & \\
\hline child(ren) & $\begin{array}{l}0.015 \\
(0.01)\end{array}$ & $\begin{array}{l}0.010 \\
(0.01)\end{array}$ & $\begin{array}{l}0.037^{*} \\
(0.02)\end{array}$ & $\begin{array}{l}0.032 \\
(0.02)\end{array}$ & & & & & & & & \\
\hline interaction: fem \#\# child(ren) & $\begin{array}{l}-0.076^{* * *} \\
(0.02)\end{array}$ & $\begin{array}{l}*-0.043^{*} \\
(0.02)\end{array}$ & $\begin{array}{l}-0.072^{*} \\
(0.03)\end{array}$ & $\begin{array}{c}-0.058^{*} \\
(0.03)\end{array}$ & & & & & & & & \\
\hline employment experience & & $\begin{array}{l}0.017 \\
(0.02)\end{array}$ & & $\begin{array}{l}0.056^{*} \\
(0.03)\end{array}$ & & $\begin{array}{l}0.022 \\
(0.08)\end{array}$ & & $\begin{array}{l}0.096 \\
(0.09)\end{array}$ & & & & \\
\hline employment experience squarec & & $\begin{array}{l}-0.004 \\
(0.00)\end{array}$ & & $\begin{array}{l}-0.021^{*} \\
(0.01)\end{array}$ & & $\begin{array}{l}-0.016 \\
(0.02)\end{array}$ & & $\begin{array}{l}-0.024 \\
(0.02)\end{array}$ & & & & \\
\hline no partner (d) & & $\begin{array}{l}0.024^{*} \\
(0.01)\end{array}$ & & $\begin{array}{l}0.010 \\
(0.02)\end{array}$ & & $\begin{array}{l}0.010 \\
(0.03)\end{array}$ & & $\begin{array}{l}0.023 \\
(0.04)\end{array}$ & & $\begin{array}{l}-0.036 \\
(0.06)\end{array}$ & & $\begin{array}{l}0.020 \\
(0.08)\end{array}$ \\
\hline employment status (ref: $F T$ ) & & & & & & & & & & & & \\
\hline parental leave & & $\begin{array}{l}-0.142^{* * * *} \\
(0.02)\end{array}$ & & $\begin{array}{l}-0.131^{\text {**** }} \\
(0.03)\end{array}$ & & $\begin{array}{l}-0.074 \\
(0.04)\end{array}$ & & $\begin{array}{l}-0.082 \\
(0.05)\end{array}$ & & $\begin{array}{l}0.007 \\
(0.06)\end{array}$ & & $\begin{array}{l}0.017 \\
(0.06)\end{array}$ \\
\hline part-time & & $\begin{array}{l}-0.019^{*} \\
(0.01)\end{array}$ & & $\begin{array}{l}0.009 \\
(0.01)\end{array}$ & & $\begin{array}{l}0.015 \\
(0.04)\end{array}$ & & $\begin{array}{l}-0.018 \\
(0.04)\end{array}$ & & $\begin{array}{l}0.023 \\
(0.06)\end{array}$ & & $\begin{array}{l}0.083 \\
(0.07)\end{array}$ \\
\hline childcare time & & $\begin{array}{l}-0.003^{* *} \\
(0.00)\end{array}$ & & $\begin{array}{l}-0.006^{* * * *} \\
(0.00)\end{array}$ & & $\begin{array}{l}-0.005^{*} \\
(0.00)\end{array}$ & & $\begin{array}{l}-0.003 \\
(0.00)\end{array}$ & & $\begin{array}{l}-0.005^{*} \\
(0.00)\end{array}$ & & $\begin{array}{l}-0.001 \\
(0.00)\end{array}$ \\
\hline net household income (log) & & $\begin{array}{l}0.050^{* * * *} \\
(0.01)\end{array}$ & & $\begin{array}{l}0.026^{*} \\
(0.01)\end{array}$ & & $\begin{array}{l}0.014 \\
(0.02)\end{array}$ & & $\begin{array}{l}0.076^{*} \\
(0.03)\end{array}$ & & $\begin{array}{l}0.014 \\
(0.02)\end{array}$ & & $\begin{array}{l}0.061 \\
(0.05)\end{array}$ \\
\hline leave experience & & $\begin{array}{l}0.003 \\
(0.00)\end{array}$ & & $\begin{array}{l}0.008^{*} \\
(0.00)\end{array}$ & & $\begin{array}{l}-0.016 \\
(0.02)\end{array}$ & & $\begin{array}{l}-0.008 \\
(0.02)\end{array}$ & & $\begin{array}{l}-0.011 \\
(0.02)\end{array}$ & & $\begin{array}{l}-0.039 \\
(0.02)\end{array}$ \\
\hline employer change (d) & & $\begin{array}{l}0.019^{*} \\
(0.01)\end{array}$ & & $\begin{array}{l}-0.020 \\
(0.01)\end{array}$ & & $\begin{array}{l}-0.009 \\
(0.02)\end{array}$ & & $\begin{array}{l}-0.035 \\
(0.03)\end{array}$ & & $\begin{array}{l}-0.005 \\
(0.02)\end{array}$ & & $\begin{array}{l}-0.045 \\
(0.03)\end{array}$ \\
\hline firm size ( $r e f .<20)$ & & & & & & & & & & & & \\
\hline $21-200$ & & $\begin{array}{l}0.019 \\
(0.01)\end{array}$ & & $\begin{array}{l}0.046^{*} \\
(0.02)\end{array}$ & & $\begin{array}{l}0.120^{* * * *} \\
(0.03)\end{array}$ & & $\begin{array}{l}-0.058 \\
(0.04)\end{array}$ & & $\begin{array}{l}0.074 \\
(0.06)\end{array}$ & & $\begin{array}{l}-0.156^{*} \\
(0.07)\end{array}$ \\
\hline $201-2000$ & & $\begin{array}{l}0.057^{\text {**** }} \\
(0.01)\end{array}$ & & $\begin{array}{l}0.058^{* *} \\
(0.02)\end{array}$ & & $\begin{array}{l}-0.004 \\
(0.04)\end{array}$ & & $\begin{array}{l}0.013 \\
(0.05)\end{array}$ & & $\begin{array}{l}0.042 \\
(0.06)\end{array}$ & & $\begin{array}{l}-0.078 \\
(0.07)\end{array}$ \\
\hline $2001+$ & & $\begin{array}{l}0.090^{\text {**** }} \\
(0.02)\end{array}$ & & $\begin{array}{l}0.105^{* * *} \\
(0.02)\end{array}$ & & $\begin{array}{l}0.038 \\
(0.05)\end{array}$ & & $\begin{array}{l}0.021 \\
(0.07)\end{array}$ & & $\begin{array}{l}0.135 \\
(0.09)\end{array}$ & & $\begin{array}{l}0.022 \\
(0.10)\end{array}$ \\
\hline NA & & $\begin{array}{l}0.001 \\
(0.01)\end{array}$ & & $\begin{array}{l}0.007 \\
(0.02)\end{array}$ & & $\begin{array}{l}0.014 \\
(0.03)\end{array}$ & & $\begin{array}{l}-0.004 \\
(0.04)\end{array}$ & & $\begin{array}{l}-0.000 \\
(0.05)\end{array}$ & & $\begin{array}{l}-0.067 \\
(0.07)\end{array}$ \\
\hline public sector (d) & & $\begin{array}{l}0.051^{\text {**** }} \\
(0.01)\end{array}$ & & $\begin{array}{l}0.027 \\
(0.02)\end{array}$ & & $\begin{array}{l}0.037 \\
(0.04)\end{array}$ & & $\begin{array}{l}0.003 \\
(0.04)\end{array}$ & & $\begin{array}{l}0.029 \\
(0.07)\end{array}$ & & $\begin{array}{l}0.003 \\
(0.08)\end{array}$ \\
\hline self-employed (d) & & $\begin{array}{l}-0.012 \\
(0.01)\end{array}$ & & $\begin{array}{l}-0.001 \\
(0.02)\end{array}$ & & $\begin{array}{l}-0.030 \\
(0.04)\end{array}$ & & $\begin{array}{l}-0.096^{*} \\
(0.05)\end{array}$ & & $\begin{array}{l}-0.017 \\
(0.07)\end{array}$ & & $\begin{array}{l}-0.059 \\
(0.08)\end{array}$ \\
\hline leadership position (d) & & $\begin{array}{l}0.061^{\text {**:** }} \\
(0.01)\end{array}$ & & $\begin{array}{l}0.030^{*} \\
(0.01)\end{array}$ & & $\begin{array}{l}-0.004 \\
(0.04)\end{array}$ & & $\begin{array}{l}-0.031 \\
(0.04)\end{array}$ & & $\begin{array}{l}0.050 \\
(0.06)\end{array}$ & & $\begin{array}{l}-0.104 \\
(0.07)\end{array}$ \\
\hline non-permanent contract (d) & & $\begin{array}{l}0.008 \\
(0.01)\end{array}$ & & $\begin{array}{l}-0.016 \\
(0.01)\end{array}$ & & $\begin{array}{l}0.056^{*} \\
(0.02)\end{array}$ & & $\begin{array}{l}0.011 \\
(0.03)\end{array}$ & & $\begin{array}{l}0.061 \\
(0.05)\end{array}$ & & $\begin{array}{l}-0.059 \\
(0.06)\end{array}$ \\
\hline childcare rate $0-3$ & & $\begin{array}{l}-0.002^{* * * *} \\
(0.00)\end{array}$ & & $\begin{array}{l}-0.003^{* * * *} \\
(0.00)\end{array}$ & & $\begin{array}{l}-0.004^{*} \\
(0.00)\end{array}$ & & $\begin{array}{l}-0.004 \\
(0.00)\end{array}$ & & $\begin{array}{l}0.002 \\
(0.00)\end{array}$ & & $\begin{array}{l}0.003 \\
(0.00)\end{array}$ \\
\hline childcare rate $4-7$ & & $\begin{array}{l}0.002^{* *} \\
(0.00)\end{array}$ & & $\begin{array}{l}0.002 \\
(0.00)\end{array}$ & & $\begin{array}{l}0.005 \\
(0.00)\end{array}$ & & $\begin{array}{l}0.008^{*} \\
(0.00)\end{array}$ & & $\begin{array}{l}0.008^{*} \\
(0.00)\end{array}$ & & $\begin{array}{l}0.009 \\
(0.01)\end{array}$ \\
\hline unemployment rate & & $\begin{array}{l}0.000 \\
(0.00)\end{array}$ & & $\begin{array}{l}-0.002 \\
(0.00)\end{array}$ & & $\begin{array}{l}-0.016^{*} \\
(0.01)\end{array}$ & & $\begin{array}{l}0.027^{* * *} \\
(0.01)\end{array}$ & & $\begin{array}{l}-0.022 \\
(0.01)\end{array}$ & & $\begin{array}{l}0.028 \\
(0.02)\end{array}$ \\
\hline childbirth & & & & & $\begin{array}{l}-0.244^{* * *} \\
(0.03)\end{array}$ & $\begin{array}{l}-0.115^{* *} \\
(0.04)\end{array}$ & $\begin{array}{l}{ }^{*}-0.228^{* * *} \\
(0.03)\end{array}$ & $\begin{array}{l}-0.091 \\
(0.04)\end{array}$ & $\begin{array}{l}{ }^{-}-0.249^{* *} \\
(0.05)\end{array}$ & $\begin{array}{c}* *-0.108 \\
(0.06)\end{array}$ & $\begin{array}{l}-0.163^{* * *} \\
(0.06)\end{array}$ & $\begin{array}{l}*-0.033 \\
(0.07)\end{array}$ \\
\hline occupational change (d) & & & & & & $\begin{array}{l}0.085^{* * *} \\
(0.03)\end{array}$ & & $\begin{array}{l}0.053 \\
(0.03)\end{array}$ & & $\begin{array}{l}0.048 \\
(0.03)\end{array}$ & & $\begin{array}{l}0.048 \\
(0.04)\end{array}$ \\
\hline _cons & $\begin{array}{l}0.295^{* * * *} \\
(0.01)\end{array}$ & $\begin{array}{l}-0.485^{* * *} \\
(0.13)\end{array}$ & $\begin{array}{l}0.383^{* * *} \\
(0.01)\end{array}$ & $\begin{array}{l}0.303 \\
(0.20) \\
\end{array}$ & $\begin{array}{l}0.446^{* * * *} \\
(0.00)\end{array}$ & $\begin{array}{l}0.124 \\
(0.31) \\
\end{array}$ & $\begin{array}{l}0.517^{* * *} \\
(0.01)\end{array}$ & $\begin{array}{l}-0.988^{*} \\
(0.43) \\
\end{array}$ & & & & \\
\hline $\bar{N}$ & 28333 & 28333 & 14693 & 14693 & 9689 & 9689 & 5421 & 5421 & 8729 & 8729 & 4992 & 4992 \\
\hline N_g & & & & & 1647 & 1647 & 859 & 859 & 1252 & 1252 & 686 & 686 \\
\hline r2_a & 0.00 & 0.07 & 0.00 & 0.04 & 0.01 & 0.02 & 0.01 & 0.02 & & & & \\
\hline $\mathrm{p}$ & 0.00 & 0.00 & 0.00 & 0.00 & 0.00 & 0.00 & 0.00 & 0.00 & & & & \\
\hline
\end{tabular}

Note: Standard errors in parentheses. Source: NEPS:SC6:12.1.0, own calculations

${ }^{*} p<0.05,{ }^{* *} p<0.01,{ }^{* * *} p<0.001$ 


\section{Check 2: Occupational sex segregation and the parenthood training penalty}

In Germany, occupations contribute strongly to the social stratification in the labour market by providing a close link between education and labour market entry into jobs with specific income and career profiles (Kleinert et al. 2021). The unequal distribution of women and men across occupations is believed to generate and reinforce new and old gender inequalities, with femaletypical occupations linked to cumulative disadvantages over the life course. More precisely, higher shares of females have been found to correlate with lower wages, part-time employment and employment trajectories (ibid.). Information on the share of women in respondent's occupation were estimated using the German Microcensus data (2012 to 2016), an obligatory yearly survey conducted by the German Federal Statistical Agency containing a two-per centsample of the population living in Germany (KldB 2010, 3-digit level). ${ }^{1}$ As expected, men worked primarily in male-dominated occupations (share of women <30 \%) whereas women tended to work in mixed (30-70\%) and female-dominated occupations (>70 \%) (Table A4A5). Additionally, respondents in female-dominated occupations were more likely to train than those in balanced and male-dominated occupations (Table A6).

Figure A3 and Table A14 displays the results from FE regression models distinguishing males and females in male-dominated, mixed and female-dominated occupations. Unadjusted models did not reveal substantial differences in fatherhood or motherhood penalties according to occupational sex-segregation. If at all, adjusted parenthood penalties were smaller in femaledominated occupations than in male-dominated and mixed occupations. Although females' effect sizes remained substantial, the results were based on small subsamples, resulting in large confidence intervals and statistically significant estimates only for women in mixed occupations.

\footnotetext{
${ }^{1}$ Since the indicator for years prior to 2012 differs from the KldB-2010, 2012 values are used for years 2009-2011. Equivalently, the latest available information for 2016 is used for 2017-2020. However, trend analyses show that the change in the occupational sex segregation varies little over time (Kleinert et al. 2021).
} 

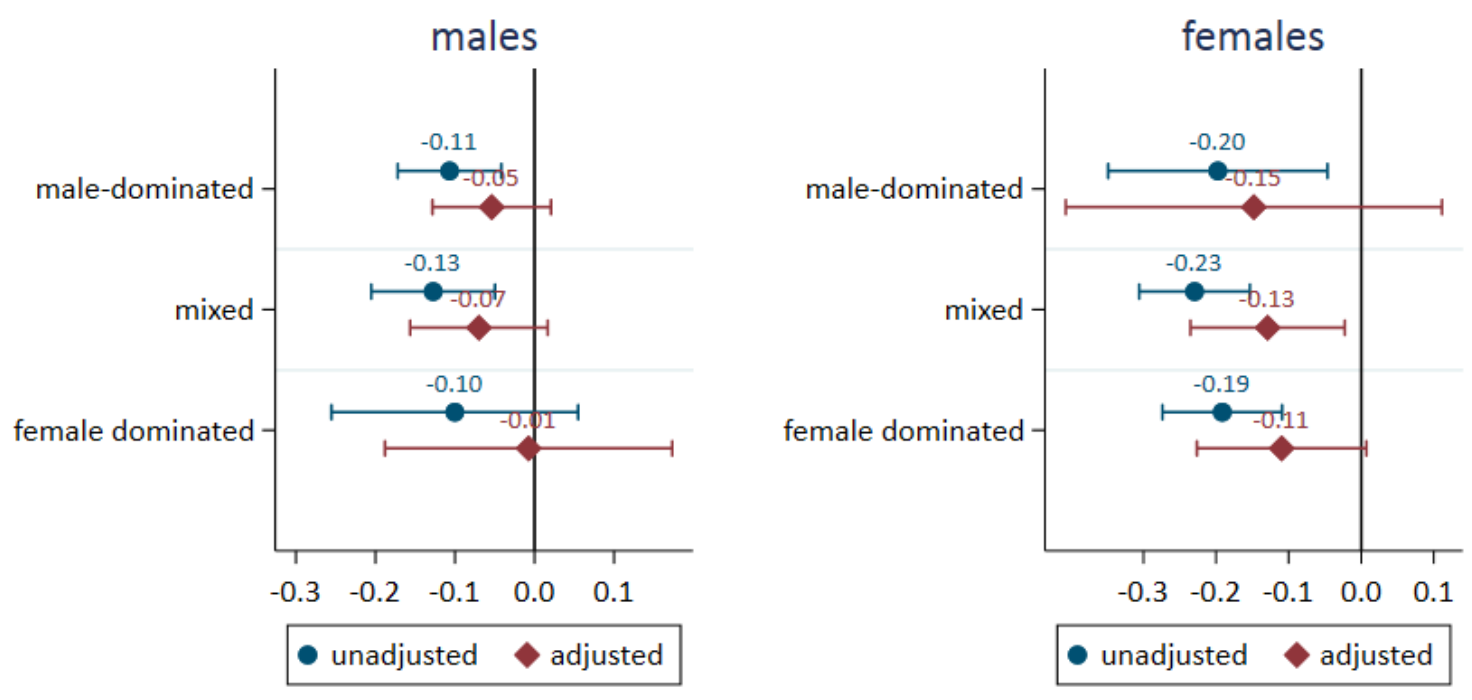

Figure A3. Parenthood training penalties across occupational sex-segregation (FE models) Source: NEPS:SC6:12.1.0, own calculations. See Tables A14-A15 in the Online Appendix. 
Table A14. Change in job related training participation by occupational gender segregation - FE regression models (males)

\begin{tabular}{|c|c|c|c|c|c|c|c|c|c|c|c|c|}
\hline \multirow[b]{3}{*}{ childbirth } & \multicolumn{4}{|c|}{ male-dominated occupation } & \multicolumn{4}{|c|}{ gender-balanced occupation } & \multicolumn{4}{|c|}{ female-dominated occupation } \\
\hline & \multicolumn{2}{|c|}{ M1 } & \multicolumn{2}{|c|}{$\mathrm{M} 2$} & \multicolumn{2}{|c|}{$\mathrm{M} 1$} & \multicolumn{2}{|c|}{$\mathrm{M} 2$} & \multicolumn{2}{|c|}{ M1 } & \multicolumn{2}{|c|}{$\mathrm{M} 2$} \\
\hline & $-0.11^{* *}$ & $(0.03)$ & -0.05 & $(0.04)$ & $-0.13^{* *}$ & $(0.04)$ & -0.07 & $(0.04)$ & -0.10 & $(0.08)$ & -0.01 & $(0.09)$ \\
\hline no partner (d) & & & 0.01 & $(0.03)$ & & & 0.00 & $(0.04)$ & & & -0.00 & $(0.07)$ \\
\hline \multicolumn{13}{|l|}{$\begin{array}{l}\text { employment status } \\
\text { (ref. full-time) }\end{array}$} \\
\hline parental leave & & & -0.09 & $(0.07)$ & & & 0.05 & $(0.08)$ & & & -0.18 & $(0.19)$ \\
\hline part-time & & & -0.08 & $(0.04)$ & & & -0.00 & $(0.05)$ & & & 0.05 & $(0.09)$ \\
\hline childcare time & & & -0.00 & $(0.00)$ & & & 0.00 & $(0.01)$ & & & -0.01 & $(0.01)$ \\
\hline leave experience & & & -0.07 & $(0.07)$ & & & 0.03 & $(0.07)$ & & & -0.02 & $(0.30)$ \\
\hline net household income (log) & & & -0.02 & $(0.03)$ & & & 0.01 & $(0.02)$ & & & -0.02 & $(0.04)$ \\
\hline occupational change $(\mathrm{d})$ & & & $0.07^{*}$ & $(0.03)$ & & & $0.10^{* *}$ & $(0.04)$ & & & 0.04 & $(0.08)$ \\
\hline employer change (d) & & & -0.02 & $(0.02)$ & & & -0.05 & $(0.03)$ & & & 0.00 & $(0.06)$ \\
\hline \multicolumn{13}{|l|}{ firm size } \\
\hline $21-200($ ref. $<20)$ & & & 0.08 & $(0.05)$ & & & -0.03 & $(0.06)$ & & & 0.05 & $(0.10)$ \\
\hline $201+$ & & & $0.11^{*}$ & $(0.05)$ & & & 0.01 & $(0.06)$ & & & 0.21 & $(0.11)$ \\
\hline NA & & & 0.03 & $(0.05)$ & & & -0.07 & $(0.06)$ & & & $0.24^{*}$ & $(0.09)$ \\
\hline public sector (d) & & & $0.16^{*}$ & $(0.08)$ & & & 0.05 & $(0.08)$ & & & 0.04 & $(0.10)$ \\
\hline self-employed (d) & & & 0.06 & $(0.08)$ & & & 0.01 & $(0.07)$ & & & 0.02 & $(0.16)$ \\
\hline leadership position (d) & & & 0.03 & $(0.04)$ & & & -0.02 & $(0.05)$ & & & $-0.17^{*}$ & $(0.08)$ \\
\hline non-permanent contract (d) & & & 0.01 & $(0.04)$ & & & 0.09 & $(0.05)$ & & & -0.01 & $(0.09)$ \\
\hline work experience & & & 0.01 & $(0.08)$ & & & 0.03 & $(0.09)$ & & & -0.27 & $(0.18)$ \\
\hline work experience squared & & & -0.01 & $(0.02)$ & & & 0.00 & $(0.02)$ & & & 0.07 & $(0.04)$ \\
\hline childcare rate $0-3$ & & & $-0.01^{* *}$ & $(0.00)$ & & & $-0.01^{* *}$ & $(0.00)$ & & & $-0.01^{*}$ & $(0.01)$ \\
\hline childcare rate 4-7 & & & 0.00 & $(0.00)$ & & & $0.01^{\text {**** }}$ & $(0.00)$ & & & $0.02^{*}$ & $(0.01)$ \\
\hline unemployment rate & & & -0.00 & $(0.01)$ & & & $0.04^{* * * *}$ & $(0.01)$ & & & -0.02 & $(0.02)$ \\
\hline _cons & $0.41^{* * * *}$ & $(0.01)$ & 0.38 & $(0.36)$ & $0.45^{* * * *}$ & $(0.01)$ & $-0.84^{*}$ & $(0.39)$ & $0.47^{* * * *}$ & $(0.01)$ & -0.35 & $(0.74)$ \\
\hline $\bar{N}$ & \multicolumn{2}{|c|}{8139} & \multicolumn{2}{|c|}{8139} & \multicolumn{2}{|c|}{5993} & \multicolumn{2}{|c|}{5993} & \multicolumn{2}{|c|}{1586} & \multicolumn{2}{|c|}{1586} \\
\hline N_g & \multicolumn{2}{|c|}{1516} & \multicolumn{2}{|c|}{1516} & \multicolumn{2}{|c|}{1179} & \multicolumn{2}{|c|}{1179} & \multicolumn{2}{|c|}{336} & \multicolumn{2}{|c|}{336} \\
\hline N_clust & \multicolumn{2}{|c|}{1729} & \multicolumn{2}{|c|}{1729} & \multicolumn{2}{|c|}{1330} & 13 & & 3 & & & \\
\hline $\mathrm{F}^{-}$ & 10 & & & & & & 3. & & 1. & & & \\
\hline r2_w & 0. & & & & & & 0 . & & 0 . & & & \\
\hline $\mathrm{p}$ & 0. & & & & 0 . & & 0 . & & 0 . & & & \\
\hline
\end{tabular}

Note: Robust standard errors in parentheses. Source: NEPS:SC6:12.1.0, own calculations

${ }^{*} p<0.05,{ }^{* *} p<0.01,{ }^{* * *} p<0.001$ 
Table A15. Change in job related training participation by occupational gender segregation - FE regression models (females)

\begin{tabular}{|c|c|c|c|c|c|c|c|c|c|c|c|c|}
\hline \multirow[b]{3}{*}{ childbirth } & \multicolumn{4}{|c|}{ male-dominated occupation } & \multicolumn{4}{|c|}{ gender-balanced occupation } & \multicolumn{4}{|c|}{ female-dominated occupation } \\
\hline & \multicolumn{2}{|c|}{ M1 } & \multicolumn{2}{|c|}{$\mathrm{M} 2$} & \multicolumn{2}{|c|}{ M1 } & \multicolumn{2}{|c|}{$\mathrm{M} 2$} & \multicolumn{2}{|c|}{ M1 } & \multicolumn{2}{|c|}{$\mathrm{M} 2$} \\
\hline & $-0.20^{*}$ & $(0.08)$ & -0.15 & $(0.13)$ & $-0.23^{* * * *}$ & $(0.04)$ & $-0.13^{*}$ & $(0.05)$ & $-0.19^{* * *}$ & $(0.04)$ & -0.11 & $(0.06)$ \\
\hline no partner (d) & & & 0.14 & $(0.13)$ & & & 0.01 & $(0.04)$ & & & 0.04 & $(0.04)$ \\
\hline \multicolumn{13}{|l|}{ employment status } \\
\hline parental leave (ref. full-time) & & & 0.04 & $(0.13)$ & & & $-0.14^{*}$ & $(0.06)$ & & & -0.12 & $(0.07)$ \\
\hline part-time & & & -0.11 & $(0.12)$ & & & -0.00 & $(0.04)$ & & & 0.03 & $(0.04)$ \\
\hline childcare time & & & -0.01 & $(0.01)$ & & & $-0.01^{*}$ & $(0.00)$ & & & -0.00 & $(0.00)$ \\
\hline leave experience & & & 0.07 & $(0.05)$ & & & -0.00 & $(0.02)$ & & & -0.02 & $(0.03)$ \\
\hline net household income $(\log )$ & & & 0.06 & $(0.03)$ & & & 0.03 & $(0.02)$ & & & 0.03 & $(0.03)$ \\
\hline occupational change $(\mathrm{d})$ & & & -0.01 & $(0.07)$ & & & $0.08^{*}$ & $(0.03)$ & & & 0.06 & $(0.03)$ \\
\hline employer change (d) & & & -0.07 & $(0.06)$ & & & 0.02 & $(0.02)$ & & & $-0.06^{*}$ & $(0.02)$ \\
\hline \multicolumn{13}{|l|}{ firm size } \\
\hline $21-200($ ref. $<20)$ & & & -0.18 & $(0.12)$ & & & 0.01 & $(0.04)$ & & & $0.10^{*}$ & $(0.04)$ \\
\hline $201+$ & & & 0.05 & $(0.12)$ & & & -0.03 & $(0.05)$ & & & -0.01 & $(0.06)$ \\
\hline NA & & & -0.10 & $(0.12)$ & & & -0.02 & $(0.04)$ & & & 0.01 & $(0.04)$ \\
\hline public sector (d) & & & -0.17 & $(0.22)$ & & & -0.06 & $(0.05)$ & & & -0.01 & $(0.06)$ \\
\hline self-employed (d) & & & -0.06 & $(0.10)$ & & & -0.02 & $(0.05)$ & & & -0.03 & $(0.05)$ \\
\hline leadership position (d) & & & 0.06 & $(0.10)$ & & & 0.00 & $(0.03)$ & & & 0.04 & $(0.04)$ \\
\hline non-permanent contract (d) & & & 0.15 & $(0.20)$ & & & -0.03 & $(0.10)$ & & & 0.17 & $(0.09)$ \\
\hline work experience & & & -0.03 & $(0.05)$ & & & -0.01 & $(0.02)$ & & & -0.04 & $(0.02)$ \\
\hline work experience squared & & & $-0.01^{*}$ & $(0.01)$ & & & -0.00 & $(0.00)$ & & & $-0.01^{* *}$ & $(0.00)$ \\
\hline childcare rate $0-3$ & & & 0.00 & $(0.01)$ & & & 0.00 & $(0.00)$ & & & $0.01^{*}$ & $(0.00)$ \\
\hline childcare rate 4-7 & & & -0.00 & $(0.02)$ & & & 0.00 & $(0.01)$ & & & -0.00 & $(0.01)$ \\
\hline unemployment rate & & & & & & & 0.04 & $(0.05)$ & & & 0.08 & $(0.05)$ \\
\hline _cons & $0.45^{* * *}$ & $(0.01)$ & 0.05 & $(0.78)$ & $0.47^{* * * *}$ & $(0.01)$ & 0.17 & $(0.38)$ & $0.47^{* * * *}$ & $(0.01)$ & -0.40 & $(0.41)$ \\
\hline $\bar{N}$ & \multicolumn{2}{|c|}{1481} & \multicolumn{2}{|c|}{1481} & \multicolumn{2}{|c|}{6579} & \multicolumn{2}{|c|}{6579} & \multicolumn{2}{|c|}{6587} & \multicolumn{2}{|c|}{6587} \\
\hline N_g & \multicolumn{2}{|c|}{345} & \multicolumn{2}{|c|}{345} & \multicolumn{2}{|c|}{1333} & \multicolumn{2}{|c|}{1333} & \multicolumn{2}{|c|}{1349} & \multicolumn{2}{|c|}{1349} \\
\hline N_clust & \multicolumn{2}{|c|}{365} & \multicolumn{2}{|c|}{365} & \multicolumn{2}{|c|}{1506} & & & & & & \\
\hline $\mathrm{F}^{-}$ & & & & & & & & & 20 & & & \\
\hline r2_w & & & & & & & & & & & & \\
\hline $\mathrm{p}$ & & & & & & & & & 0 . & & & \\
\hline
\end{tabular}




\section{Check 3: Training participation across firms with and without supportive measures}

To examine the potentially positive role of supportive workplace characteristics, FE-regression models were re-estimated distinguishing between respondents in organisations with or without (a) provision or financing of courses, (b) education planning on a regular basis, (c) a company agreement about further education, or (d) a unit or staff member responsible for organising training. Men and women were similarly likely to report working in firms with the relevant characteristics. However, respondents working in supportive contexts were more likely to participate in job-related training than respondents in contexts without support (Table A17). However, this relationship was less pronounced for women than men.

Figure A4 displays the results from separate FE regression models distinguishing men (first row) and women (second row) with an employer providing (right panel) and not providing support measures (left panel). Baseline models without time-varying control variables showed somewhat larger parenthood training penalties for individuals working in more supportive contexts compared to smaller training disparities in less supportive contexts. These differences were particularly pronounced for mothers. However, the observed fatherhood penalties were again strongly associated with other time-varying characteristics, as the coefficients in full models were reduced and no longer statistically significant. For women, time-varying variables also reduced the size of the coefficients. However, the effects remained substantial in magnitude and statistically significant. Additional analyses showed more pronounced and statistically significant motherhood training differences for contexts providing at least two out of four support measures (Figure A5).

In sum, the results suggest that parents, and especially mothers, experienced greater training penalties when working in more supportive contexts and, thus in environments with higher overall training participation, than parents working in contexts with fewer or no support and therefore lower training rates. 

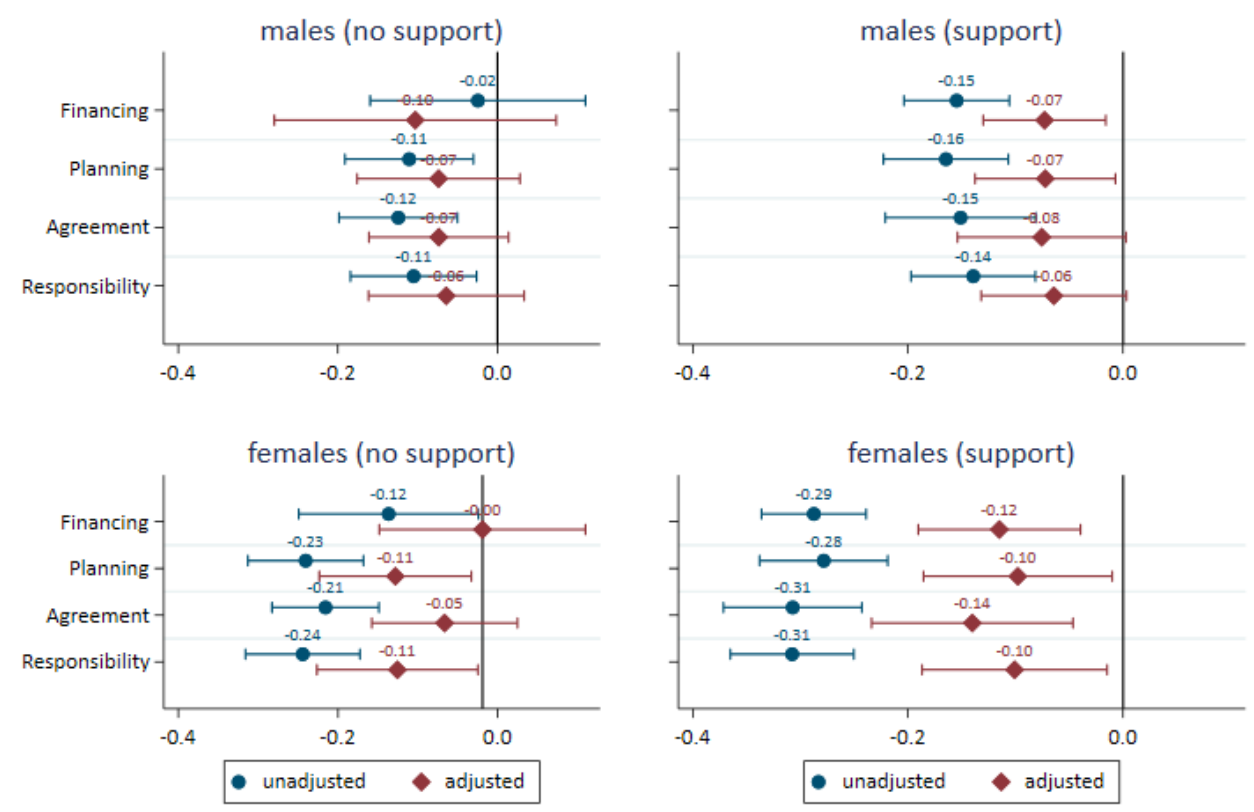

Figure A4. Parenthood training penalties by employer's support of job-related training (FE models)

Source: NEPS:SC6:12.1.0, own calculations.

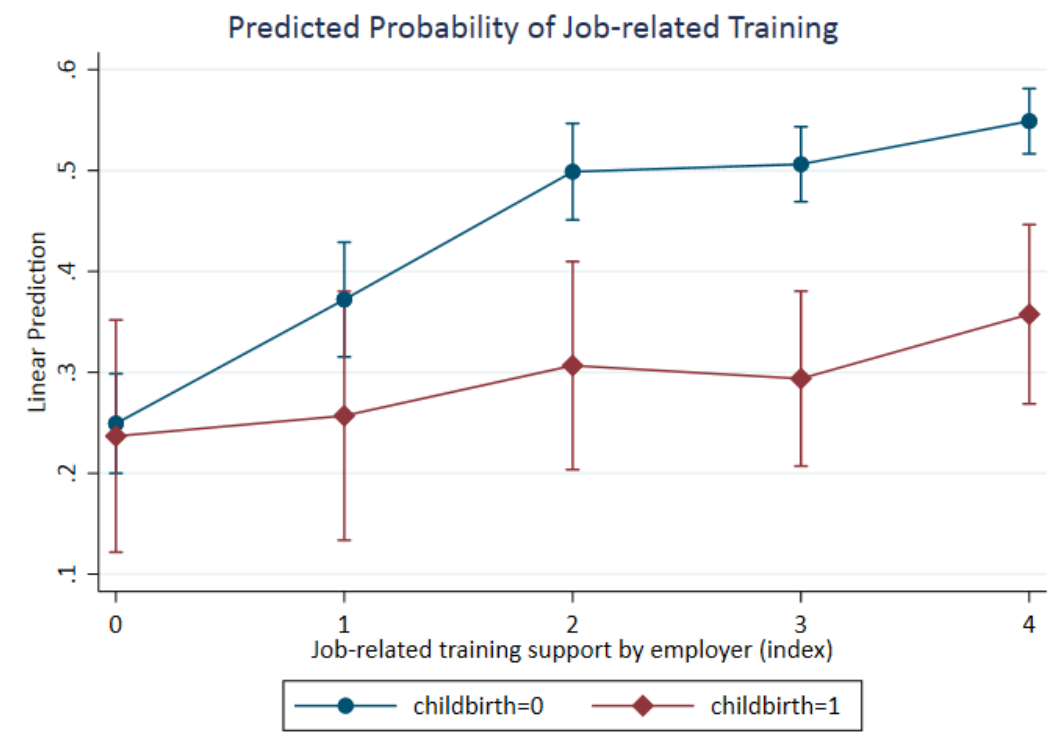

Figure A5. Motherhood training penalties across the intensity of employer's training support (FE models)

Source: NEPS:SC6:12.1.0, own calculations. 
Table A16. Firm characteristics by parenthood status (within sample, unweighted)

\begin{tabular}{|c|c|c|c|c|c|c|c|c|}
\hline & \multicolumn{4}{|c|}{ Men } & \multicolumn{4}{|c|}{ Women } \\
\hline & \multicolumn{2}{|c|}{ childless/before } & \multicolumn{2}{|c|}{ after childbirth } & \multicolumn{2}{|c|}{ childless/before } & \multicolumn{2}{|c|}{ after childbirth } \\
\hline & mean/\% & $\mathrm{sd}$ & mean $/ \%$ & $\mathrm{sd}$ & mean $/ \%$ & $\mathrm{sd}$ & mean $/ \%$ & $\mathrm{sd}$ \\
\hline Financing & 0.86 & 0.34 & 0.87 & 0.34 & 0.81 & 0.39 & 0.82 & 0.39 \\
\hline Planning & 0.67 & 0.47 & 0.65 & 0.48 & 0.65 & 0.48 & 0.63 & 0.48 \\
\hline Agreement & 0.56 & 0.50 & 0.55 & 0.50 & 0.57 & 0.50 & 0.58 & 0.49 \\
\hline Responsibility & 0.70 & 0.46 & 0.68 & 0.47 & 0.62 & 0.49 & 0.61 & 0.49 \\
\hline Observations & \multicolumn{2}{|c|}{10410} & \multicolumn{2}{|c|}{2457} & \multicolumn{2}{|c|}{10360} & \multicolumn{2}{|c|}{2118} \\
\hline
\end{tabular}

Source: NEPS:SC6:12.1.0, own calculation, unweighted.

Table A17. Training participation across firms with and without supportive measures (in percent, unweighted)

\begin{tabular}{|c|c|c|c|c|c|c|c|c|c|c|c|c|c|c|c|c|}
\hline \multirow[b]{4}{*}{ Firm attribute } & \multicolumn{8}{|c|}{ Men } & \multicolumn{8}{|c|}{ Women } \\
\hline & \multicolumn{4}{|c|}{ not provided } & \multicolumn{4}{|c|}{$\begin{array}{l}\text { provided } \\
\end{array}$} & \multicolumn{4}{|c|}{$\begin{array}{l}\text { not provided } \\
\end{array}$} & \multicolumn{4}{|c|}{ provided } \\
\hline & \multicolumn{2}{|c|}{ childless/before } & \multicolumn{2}{|c|}{ after childbirth } & \multicolumn{2}{|c|}{ childless/before } & \multicolumn{2}{|c|}{ after childbirth } & \multicolumn{2}{|c|}{ childless/before } & \multicolumn{2}{|c|}{ after childbirth } & \multicolumn{2}{|c|}{ childless/before } & \multicolumn{2}{|c|}{ after childbirth } \\
\hline & $\%$ & sd & $\%$ & sd & $\%$ & sd & $\%$ & sd & $\%$ & sd & $\%$ & sd & $\%$ & sd & $\%$ & sd \\
\hline Financing & 0.27 & 0.01 & 0.24 & 0.02 & 0.44 & 0.01 & 0.43 & 0.01 & 0.30 & 0.01 & 0.25 & 0.02 & 0.49 & 0.01 & 0.36 & 0.01 \\
\hline Planning & 0.34 & 0.01 & 0.33 & 0.02 & 0.45 & 0.01 & 0.45 & 0.01 & 0.38 & 0.01 & 0.28 & 0.02 & 0.49 & 0.01 & 0.38 & 0.01 \\
\hline Agreement & 0.36 & 0.01 & 0.34 & 0.01 & 0.45 & 0.01 & 0.47 & 0.01 & 0.40 & 0.01 & 0.27 & 0.02 & 0.50 & 0.01 & 0.39 & 0.01 \\
\hline Responsibility & 0.33 & 0.01 & 0.34 & 0.02 & 0.45 & 0.01 & 0.44 & 0.01 & 0.40 & 0.01 & 0.29 & 0.02 & 0.48 & 0.01 & 0.37 & 0.01 \\
\hline
\end{tabular}

Source: NEPS:SC6:12.1.0, own calculation, unweighted. 
Table A18. Change in job related training participation for individuals with employer support - FE regression models (males)

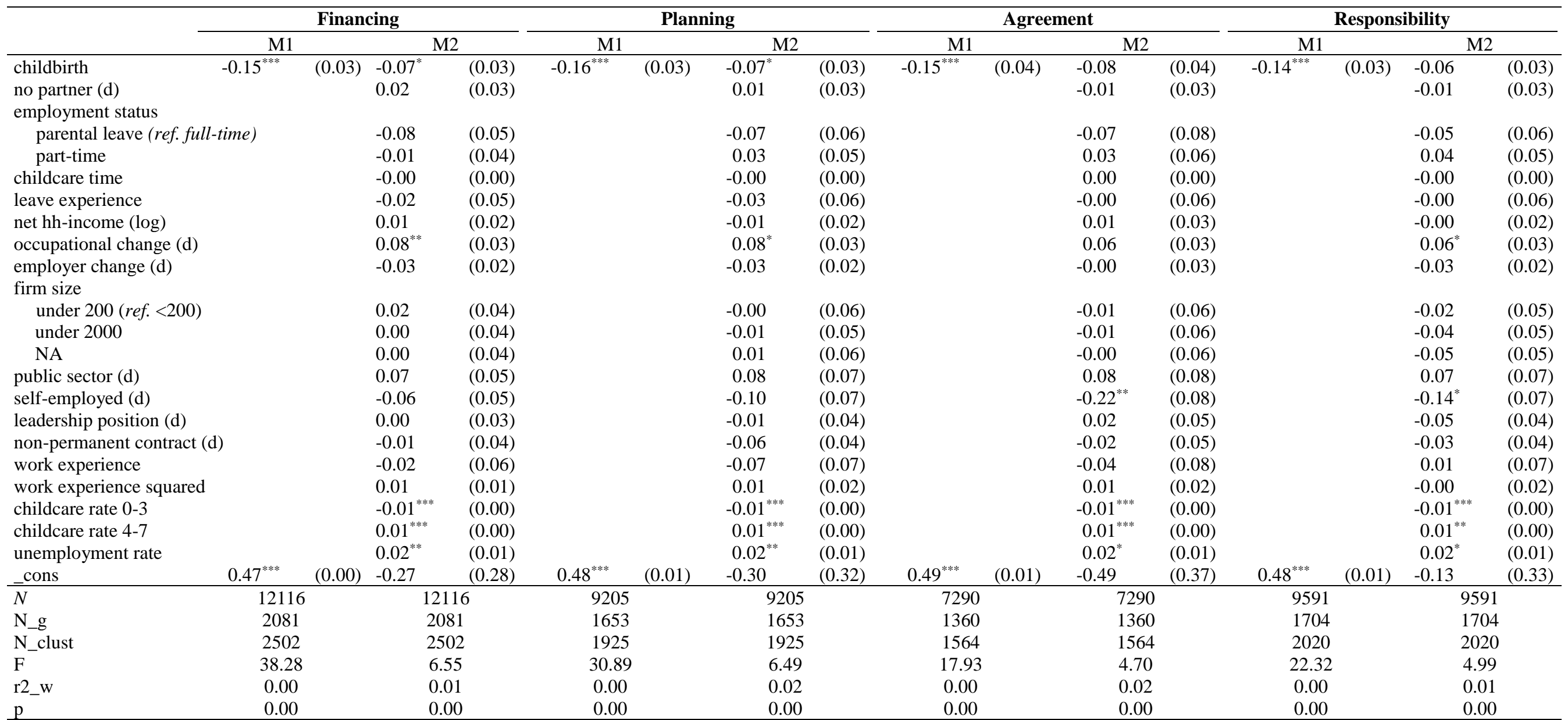

Note: Robust standard errors in parentheses. Source: NEPS:SC6:12.1.0, own calculations

${ }^{*} p<0.05,{ }^{* *} p<0.01,{ }^{* * *} p<0.001$ 
Table A19. Change in job related training participation for individuals with employer support - FE regression models (females)

\begin{tabular}{|c|c|c|c|c|c|c|c|c|c|c|c|c|c|c|c|c|}
\hline \multirow[b]{3}{*}{ childbirth } & \multicolumn{4}{|c|}{ Financing } & \multicolumn{4}{|c|}{ Planning } & \multicolumn{4}{|c|}{ Agreement } & \multicolumn{4}{|c|}{ Responsibility } \\
\hline & \multicolumn{2}{|l|}{ M1 } & \multicolumn{2}{|c|}{$\mathrm{M} 2$} & \multicolumn{2}{|c|}{ M1 } & \multicolumn{2}{|c|}{ M2 } & \multicolumn{2}{|c|}{ M1 } & \multicolumn{2}{|c|}{$\mathrm{M} 2$} & \multicolumn{2}{|c|}{ M1 } & \multicolumn{2}{|c|}{ M2 } \\
\hline & $-0.29^{* * *}$ & $(0.02)$ & $-0.12^{* *}$ & $(0.04)$ & $-0.28^{* * *}$ & $(0.03)$ & $-0.10^{*}$ & $(0.04)$ & $-0.31^{* * * *}$ & $(0.03)$ & $-0.14^{* *}$ & $(0.05)$ & $-0.31^{* * *}$ & $(0.03)$ & $-0.10^{*}$ & $(0.04)$ \\
\hline no partner $(\mathrm{d})$ & & & 0.03 & $(0.03)$ & & & 0.04 & $(0.04)$ & & & 0.02 & $(0.04)$ & & & 0.06 & $(0.04)$ \\
\hline \multicolumn{17}{|c|}{ employment status } \\
\hline parental leave (ref. full- & l-time) & & $-0.20^{* * *}$ & $(0.04)$ & & & $-0.24^{* * *}$ & $(0.05)$ & & & $-0.31^{* * *}$ & $(0.05)$ & & & $-0.22^{* * *}$ & $(0.05)$ \\
\hline part-time & & & -0.02 & $(0.03)$ & & & -0.03 & $(0.03)$ & & & $-0.08^{*}$ & $(0.04)$ & & & -0.03 & $(0.03)$ \\
\hline childcare time & & & $-0.00^{*}$ & $(0.00)$ & & & -0.00 & $(0.00)$ & & & -0.00 & $(0.00)$ & & & $-0.00^{*}$ & $(0.00)$ \\
\hline leave experience & & & -0.01 & $(0.01)$ & & & -0.02 & $(0.02)$ & & & -0.02 & $(0.02)$ & & & -0.02 & $(0.02)$ \\
\hline net hh-income (log) & & & 0.03 & $(0.02)$ & & & 0.04 & $(0.02)$ & & & 0.04 & $(0.03)$ & & & $0.05^{*}$ & $(0.02)$ \\
\hline occupational change (d) & & & $0.06^{*}$ & $(0.02)$ & & & $0.07^{*}$ & $(0.03)$ & & & 0.05 & $(0.03)$ & & & 0.05 & $(0.03)$ \\
\hline employer change (d) & & & -0.02 & $(0.02)$ & & & -0.03 & $(0.02)$ & & & -0.04 & $(0.02)$ & & & -0.02 & $(0.02)$ \\
\hline \multicolumn{17}{|l|}{ firm size } \\
\hline under 200 (ref. <200) & & & 0.03 & $(0.03)$ & & & $0.12^{* *}$ & $(0.04)$ & & & 0.04 & $(0.05)$ & & & -0.03 & $(0.05)$ \\
\hline under 2000 & & & -0.04 & $(0.04)$ & & & 0.00 & $(0.05)$ & & & -0.02 & $(0.05)$ & & & $-0.12^{*}$ & $(0.05)$ \\
\hline NA & & & -0.04 & $(0.04)$ & & & 0.05 & $(0.05)$ & & & 0.04 & $(0.05)$ & & & -0.08 & $(0.05)$ \\
\hline public sector (d) & & & -0.03 & $(0.04)$ & & & 0.00 & $(0.04)$ & & & -0.05 & $(0.05)$ & & & -0.03 & $(0.04)$ \\
\hline self-employed (d) & & & 0.03 & $(0.05)$ & & & 0.06 & $(0.07)$ & & & 0.03 & $(0.07)$ & & & -0.04 & $(0.06)$ \\
\hline leadership position (d) & & & -0.05 & $(0.04)$ & & & -0.05 & $(0.05)$ & & & -0.04 & $(0.06)$ & & & -0.02 & $(0.05)$ \\
\hline non-permanent contract $(\mathrm{d}$ & & & 0.01 & $(0.03)$ & & & -0.01 & $(0.04)$ & & & -0.02 & $(0.04)$ & & & -0.01 & $(0.03)$ \\
\hline work experience squared & & & -0.02 & $(0.02)$ & & & -0.01 & $(0.02)$ & & & -0.03 & $(0.02)$ & & & 0.00 & $(0.02)$ \\
\hline childcare rate $0-3$ & & & $-0.01^{* *}$ & $(0.00)$ & & & -0.00 & $(0.00)$ & & & $-0.01^{*}$ & $(0.00)$ & & & -0.00 & $(0.00)$ \\
\hline childcare rate 4-7 & & & $0.01^{*}$ & $(0.00)$ & & & $0.01^{*}$ & $(0.00)$ & & & 0.00 & $(0.00)$ & & & 0.00 & $(0.00)$ \\
\hline unemployment rate & & & -0.00 & $(0.01)$ & & & -0.00 & $(0.01)$ & & & -0.01 & $(0.01)$ & & & -0.00 & $(0.01)$ \\
\hline _cons & $0.52^{* * *}$ & $(0.00)$ & -0.06 & $(0.30)$ & $0.52^{* * *}$ & $(0.00)$ & -0.28 & $(0.34)$ & $0.53^{* * * *}$ & $(0.01)$ & 0.13 & $(0.37)$ & $0.52^{* * * *}$ & $(0.00)$ & 0.02 & $(0.35)$ \\
\hline$N$ & \multicolumn{2}{|c|}{11140} & \multicolumn{2}{|c|}{11140} & \multicolumn{2}{|c|}{8667} & \multicolumn{2}{|c|}{8667} & \multicolumn{2}{|c|}{7277} & \multicolumn{2}{|c|}{7277} & \multicolumn{2}{|c|}{8327} & \multicolumn{2}{|c|}{8327} \\
\hline N_g & \multicolumn{2}{|l|}{2023} & \multicolumn{2}{|c|}{2023} & 1651 & & 16 & & 141 & & 14 & & $15^{7}$ & & $15^{7}$ & \\
\hline N_clust & 2327 & & & & 1850 & & 18 & & 156 & & 15 & & 179 & & 179 & \\
\hline $\mathrm{F}^{--}$ & 134.17 & & & & 84.0 & & 10. & & 87.5 & & 9. & & 110 & & 11. & \\
\hline r2_w & 0.01 & & & & 0.01 & & 0.0 & & 0.0 & & 0. & & 0.0 & & 0.0 & \\
\hline $\mathrm{p}$ & 0.00 & & 0. & & 0.00 & & 0.0 & & 0.0 & & 0. & & 0.0 & & 0.0 & \\
\hline
\end{tabular}

Note: Robust standard errors in parentheses. Source: NEPS:SC6:12.1.0, own calculations

${ }^{*} p<0.05,{ }^{* *} p<0.01,{ }^{* * *} p<0.001$ 